\title{
Intérêts et limites des fermenteurs à flux semi-continu de type Rusitec dans l'étude des fermentations du rumen
}

\author{
G. Blanchart 1, M. Durand 2, J.L. Barry ${ }^{3}$, M. Bouiller-Oudot 4 \\ et J.P. Jouany 5
}

${ }^{1}$ ENSAIA, laboratoire de la chaire de zootechnie, 2 avenue de la Forêt de Haye, 54500 Vandceuvre

${ }^{2}$ INRA, station de recherches de nutrition, Centre de Jouy-en-Josas, Domaine de Vilvert, 78350 Jouy-en-Josas

${ }^{3}$ INRA, laboratoire de technologie des aliments pour animaux, Centre de Nantes, rue de la Géraudière, 44000 Nantes

${ }^{4}$ ENSA, laboratoire du service de zootechnie et des productions animales, 145 avenue de Muret, 31000 Toulouse

${ }^{5}$ INRA, station de nutrition des herbivores, unité de la digestion microbienne, Centre de ClermontTheix, 63122 Ceyrat, France

(reçu le 21 avril 1989; accepté le 21 juillet 1989)

Résumé - Pour caractériser les possibilités d'utilisation du Rusitec, des résultats et des observations recueillis dans 5 laboratoires français mettant en œuvre cette technique ainsi que des données publiées par des auteurs de différents pays sont rassemblés et discutés. Les techniques de travail sont généralement assez proches entre laboratoires, bien que les matériels et les méthodes puissent parfois être quelque peu modifiés pour être adaptés à des objectifs de recherche particuliers : taille des mailles du tissu (50 ou $150 \mu \mathrm{m}$ ), concentrations en éléments minéraux et en urée de la solution saline... Les différences entre laboratoires de taux de renouvellement de la phase liquide ne s'expliquent pas clairement.

Le Rusitec autorise la mesure simultanée de la plupart des paramètres de fermentation : taux de disparition de la matière sèche et de ses composants, productions d'acides gras volatils, de gaz et d'ammoniac, protéosynthèse microbienne. Le Rusitec offre en outre la possibilité d'étudier à la fois des aspects cinétiques et des bilans de la fermentation. II peut être particulièrement intéressant de l'utiliser dans des études de manipulation des fermentations ruminales. Des données récentes obtenues en France montrent ainsi les effets de supplémentations en urée et de la teneur en ammoniac du milieu de fermentation sur la dégradation des aliments, les effets de subcarences en phosphore ou en soufre sur la dégradation des aliments et la protéosynthèse microbienne, les effets de l'addition de vitamines ou de ionophores sur le faciès fermentaire.

La variabilité journalière des taux de disparition des aliments et des productions d'acides gras volatils et de gaz conduisent à recommander d'effectuer des répétitions (4j pour 2 réacteurs) pour obtenir une assez bonne répétabilité entre essais et entre laboratoires. Dans ces conditions, les résultats obtenus en Rusitec sont aussi assez proches de ceux fournis par des méthodes in vivo.

Des déviations des fermentations peuvent se produire à la suite d'une sélection des souches présentes, spécialement au cours d'expériences de longue durée et lorsque les conditions ne sont pas pleinement favorables.

Les critiques qui peuvent être faites au Rusitec tiennent à l'utilisation de sachets de nylon dont la porosité pourrait soit autoriser des pertes de particules, soit freiner les échanges de gaz, de liquides et de micro-organismes entre l'intérieur et l'extérieur des sachets. Ces critiques peuvent aussi porter sur le rythme d'alimentation (1 repas /jour) qui diffère du rythme habituel d'alimentation in vivo. Dans cette 
optique, le Rusitec semble mieux adapté à l'étude de la fermentation des aliments lentement dégradables qu'à celle des aliments concentrés. Enfin, lors des essais de supplémentations, le choix du mode d'expression des additifs (sur la base du poids d'aliment, du volume de réacteur, du volume de solution saline perfusé ou de la quantité d'aliment dégradé) n'est jamais totalement satisfaisant.

La dernière question est la difficulté rencontrée pour établir une concordance entre les résultats obtenus en Rusitec et ceux fournis par les méthodes in vivo: des différences entre les 2 méthodes ne peuvent pas être attribuées directement à l'une ou à l'autre. Le Rusitec fournit des données quantitatives qui peuvent aider à la description et à l'explication des observations faites in vivo.

rumen artificiel — fermentation — digestion — ruminant — micro-organisme

Summary - Advantages and limits of the seml-continuous artificial rumen (Rusitec) for the study of rumen fermentations. The aim of the present paper is to present the different ways of using the rumen-simulation technique (Rusitec) to collect the results obtained in different laboratories, to point out the similarities and differences between results obtained with this technique and those obtained with different methods, and finally to determine the fields of application of this technique as well as its limits. Operating conditions were generally similar between laboratories, although materials and methods were sometimes slightly modified to fit with specific research targets, i.e. bag pore size $(50$ or $150 \mu \mathrm{m})$, mineral and urea contents in buffer solution.

Rusitec enables one to measure simultaneously most fermentation parameters: disappearance rate of dry matter and of its components, VFA, gas and ammonia output and microbial protein synthesis. It also allows a study of the kinetic aspects of fermentation and fermentation balances. Moreover, it can be used to study rumen manipulation. Recent data obtained in France showed the effects of urea perfusion and ammonia concentration on feed degradation, the effects of phosphorus or sulfur deficiencies on feed degradation and microbial protein synthesis, and the effects of vitamin or ionophore addition on the fermentation pattern.

Daily variations in the disappearance rates and in VFA and gas output led the recommendation that replicates ( 4 days and 2 vessels) be taken to obtain good repeatability between trials and between laboratories. Under these conditions, results obtained with Rusitec were fairly similar to those obtained in vivo.

Attention must be paid to changes in the fermentation process caused by the selection of microbial strains, particularly during long-term experiments and when treatments modify the life conditions of bacteria. The use of nylon bags is questionable as their porosity may either lead to particulate matter losses or reduce the passage of gases, liquids and bacteria. Criticism may also be applied to the frequency of feeding (1 meal per day), which differs from the usual in vivo practice. In this respect, Rusitec seems to be more suitable for studies involving slowly degradable feed (roughage) than for those using concentrates. The question of the amount of additives to be perfused is considered. Calculation of the additive concentration on the basis of the feed dry mafter, the vessel volume, buffer solution volume or amount of degraded feed is never satisfactory. Finally, it is difficult to compare in vitro data with in vivo results. Differences between the 2 methods cannot be directly attributed to one or the other. The main advantage of Rusitec is to give quantitative data on degradability and fermentation which may help to predict and explain in vivo observations.

artificial rumen - fermentation — digestion — ruminant - micro-organism

\section{INTRODUCTION}

L'étude des activités des microorganismes, indépendamment de la physiologie de l'hôte et des variations de son comportement ne peut être menée que par l'utilisation de techniques in vitro.
Parmi ces dernières, celles qui mettent en œuvre des systèmes "continus" (apports continus d'aliment et de solution tampon) ou "semi-continus" (apport continu de solution tampon et apport discontinu d'aliment) comportent 2 intérêts majeurs par rapport à celles qui font appel aux sys- 
tèmes "fermés" (de type "batch" : apport unique d'aliment et de solution tampon): elles permettent l'adaptation des microorganismes aux facteurs étudiés et elles évitent l'accumulation dans le milieu des produits de la fermentation qui risque d'entraîner très rapidement ( 3 à $5 \mathrm{~h}$ ) des déviations fermentaires. Actuellement 2 systèmes de fermentation de ce type sont utilisés.

Dans le système proposé par Hoover et al. (1976) l'apport de substrat et l'évacuation des résidus solides se produisent en continu. Deux sorties permettent l'évacuation des effluents :

- une sortie par aspiration continue à travers un filtre par laquelle est évacuée une partie des liquides sans qu'il y ait sortie de particules;

- une sortie par simple gravité par laquelle sont évacués les liquides en excès qui entraînent avec eux des particules alimentaires.

II s'établit un équilibre entre les 2 sorties. Dans ces conditions l'activité fermentaire est assez proche de celle observée in situ, spécialement pour ce qui concerne les produits de la fermentation.

Le système de Hoover et al. (1976) a été légèrement modifié par Merry et al. (1987) en Grande Bretagne. Cependant, à notre connaissance il n'est pas actuellement utilisé en France.

Czerkawski et Breckenridge (1977) ont mis au point le système Rusitec dans lequel seuls les liquides sont évacués en cours de fermentation. Les solides sont confinés dans des sachets de nylon, retenant en même temps une partie des microorganismes. Ce système a été spécialement conçu pour être d'un emploi relativement simple et aisé.

Le Rusitec est maintenant largement utilisé en France et ce rapport vise à : (i) présenter les différentes modalités de son utilisation;

(ii) rassembler les différents types de résultats qu'il est possible d'en attendre et évaluer leur fiabilité;

(iii) mettre en évidence les analogies et les différences entre les résultats obtenus par l'emploi du Rusitec et ceux obtenus par les autres méthodes couramment pratiquées;

(iv) déterminer les recherches dans lesquelles la mise en œuvre du Rusitec se révèle utile et efficace et, au contraire, les limites éventuelles à son utilisation.

Ce rapport s'appuie, outre sur les données bibliographiques étrangères, sur les résultats, publiés ou non, obtenus par les laboratoires de l'INRA :

- Laboratoire de la chaire de zootechnie de I'ENSAIA de Nancy (G. Blanchart);

- Station de recherches de nutrition de Jouy-en-Josas (M. Durand);

- Laboratoire de technologie des aliments pour animaux de Nantes (J.L. Barry);

- Laboratoire du service de zootechnie et des productions animales de l'ENSA de Toulouse (M. Bouiller-Oudot);

- Laboratoire de nutrition des herbivores de Theix (J.P. Jouany).

Ces laboratoires sont appelés, dans le texte, par le nom de la ville où ils sont localisés.

\section{MATÉRIELS ET MÉTHODES}

\section{Description générale du matériel}

Le schéma général du Rusitec est présenté Fig. 1. Dans chaque réacteur tenu au bain- 


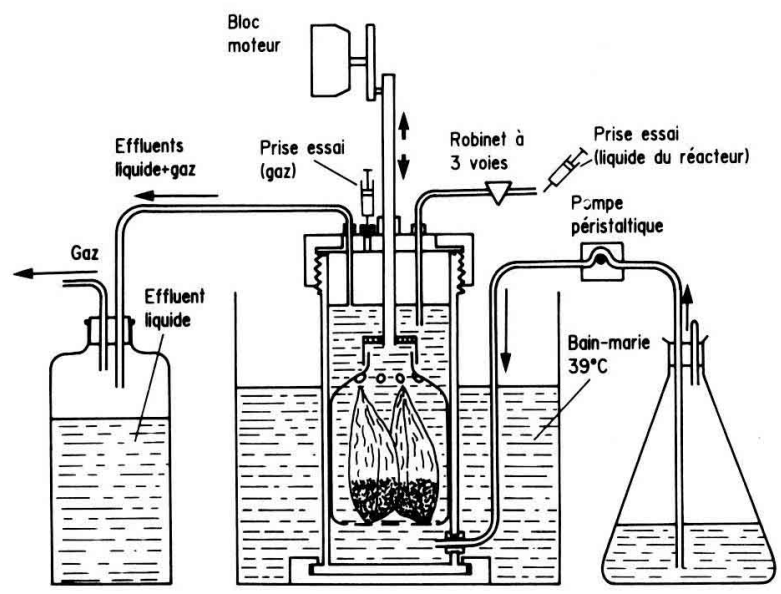

Fig. 1. Schéma général du Rusitec.

marie a $40^{\circ} \mathrm{C}$, un panier ou un flacon plastique perforé, où sont placés 2 sachets de nylon contenant l'aliment à tester, est agité d'un mouvement linéaire alternatif. Une solution saline est infusée en permanence à l'aide d'une pompe peristaltique. Les effluents liquides et gazeux sont évacués par une sortie unique et récupérés.

La méthode de mise en fonctionnement et d'approvisionnement du Rusitec a été décrite par Czerkawski et Breckenridge (1977) et rappelée par Czerkawski (1984). L'inoculum liquide est constitué pour moitié de jus de rumen grossièrement filtré et pour moitié d'un mélange de solution saline et d'eau (60/40). Le premier jour, un sachet rempli de contenu solide du rumen (inoculum solide) et un autre sachet contenant l'aliment à utiliser sont mis en place. Le lendemain, le sachet de contenu de rumen est remplacé par un sachet d'aliment. A partir de ce jour et tous les jours, le sachet ayant séjourné $48 \mathrm{~h}$, est remplacé par un sachet contenant un nouvel échantillon de l'aliment utilisé. Le sachet retiré est rincé immédiatement par de la solution saline et la phase intermédiaire ainsi récupérée est remise dans le réacteur. Cette pratique est indispensable au maintien en activité de l'inoculum.
Le modèle mis en œuvre par l'équipe de Nancy depuis 1982 présente de grandes modifications par rapport au modèle original : matériaux, organes de transmission, système de récupération des effluents ont été modifiés, et surtout, la capacité des réacteurs a été multipliée par 2,5 (Blanchart \& Vignon, 1984) (Fig. 2).

Sept fermenteurs ont depuis été fabriqués, sur les plans proposés par Czerkawski et Breckenridge (1977), par l'atelier de la station de recherches de nutrition de Jouy-en-Josas, et utilisés dans différents laboratoires. Ces fermenteurs ont été très peu modifiés par rapport au modèle original : seuls le système de transmission du mouvement (tige en teflon) et le système de récupération des effluents (séparation des gaz et des liquides par gravité et récupération des gaz dans une colonne de liquide) ont été transformés. A Jouy, un système d'électrovanne, selon le modèle développé à l'INRA de Lille par Moletta (communication personnelle), permettant la mesure cinétique de la production de gaz commence à être utilisé. A Nantes, un débitmètre à bulles permet de contrôler le débit réel de la solution tampon.

La méthode de mise en route et d'approvisionnement n'est généralement pas sensible- 


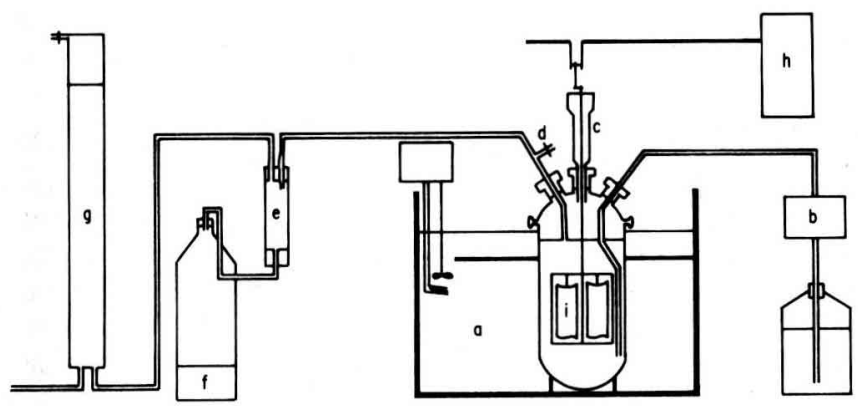

Fig. 2. Schéma général du modèle de Rusitec utilisé à Nancy (Blanchart \& Vignon, 1984) : (a) bainmarie à $40{ }^{\circ} \mathrm{C}$; (b) pompe péristaltique; (c) joint liquide; (d) prise d'échantillons; (e) séparateur de phases; (f) effluents liquides; (g) récupérateur des gaz; (h) bloc moteur; (i) panier avec 4 sachets.

ment différente de la méthode proposée par Czerkawski et Breckenridge (1977). Cependant, le remplacement des gaz par un gaz indemne d'oxygène, après approvisionnement, est généralement omis, sauf à Jouy dans le cas d'aliments peu dégradables.

\section{Inoculum}

Les animaux donneurs, porteurs d'une canule du rumen, sont des moutons adultes (race Texel ou lle de France) ou, à Nantes, des chèvres taries adultes (race Alpine chamoisée). Du contenu est prélevé sur plusieurs animaux par aspiration ou «à la cuiller" de 1 à $3 \mathrm{~h}$ après le repas, filtré à travers de la gaze, éventuellement après homogénéisation, et utilisé pour le remplissage des fermenteurs $20 \mathrm{~min}$ à $1 \mathrm{~h}$ après prélèvement. Du contenu solide de rumen placé en sachet est également utilisé comme inoculum solide et fournit au milieu des quantités importantes de micro-organismes associés à la phase solide.

Les animaux donneurs reçoivent des régimes standard comportant toujours une forte proportion de fourrage. Généralement, ils ne sont pas habitués à recevoir l'aliment pour lequel l'inoculum est utilisé. L'adaptation des bactéries de l'inoculum à l'aliment utilisé se produit in vitro en 7 à $10 \mathrm{j}$. Cependant, à Jouy, une adaptation des animaux donneurs est pratiquée dans le cas des pailles traitées à la soude ou des régimes purifiés comportant de l'urée.

\section{Sachets}

Dans la méthode originale, les auteurs préconisent l'utilisation de tissus de gaze de nylon à 1 perforation $/ \mathrm{mm}$ (Czerkawski \& Breckenridge, 1977; Czerkawski, 1984). Le diamètre des mailles, non précisé, est probablement supérieur à $500 \mu \mathrm{m}$. Aux USA, Fuller et Johnson (1981) et Schaetzel et Johnson (1981) utilisent également un tissu pour moustiquaire à mailles assez larges.

Brice et Morrison (1983) comparent des tissus de $5,24,56$ et $1000 \mu \mathrm{m}$ de vide de maille et montrent une réduction significative de la dégradation de la matière sèche de tige d'herbe avec le tissu de $5 \mu \mathrm{m}$. Entre 24 et $1000 \mu \mathrm{m}$ les variations de dégradation de la matière sèche n'étaient pas statistiquement significatives. Dans une étude ultérieure, ces mêmes auteurs utilisent un tissu de $56 \mu \mathrm{m}$ (Morrison \& Brice, 1984).

L'équipe de Toulouse a pu mettre en évidence, avec de la paille, une diminution de l'activité fermentaire lorsque la taille des mailles est réduite de 250 à $25 \mu \mathrm{m}$. Elle se traduit par une diminution du taux de disparition de la matière sèche, de la quantité d'acides gras volatils to- 
taux produite et du rapport «acide acétique/ acide propionique" (Tableau I). Cependant, entre 145 et $45 \mu \mathrm{m}$, le taux de disparition de la matière sèche de son et de pulpes d'agrumes n'est que très peu modifié, la diminution observée à Nantes n'étant pas significative (59 contre $61 \%$ pour le son et 80 contre $84 \%$ pour les pulpes d'agrume). L'équipe de Theix a cependant montré une augmentation notable des pertes particulaires lorsque la taille des mailles passe de 50 à $150 \mu \mathrm{m}$.

La taille des mailles est choisie par les différentes équipes (Tableau II) en fonction des objectifs de la recherche qui imposent ou, au contraire, interdisent de laver les sachets.
L'étude de la dégradation des matières azotées nécessite que les micro-organismes présents à l'intérieur des sachets soient éliminés; il est obligatoire de procéder à un lavage très efficace des sachets. Ce lavage ne peut être effectué sans perte excessive de résidu alimentaire que si la taille des mailles est réduite $(50 \mu \mathrm{m})$. II est alors pratiqué en machine (Theix et Nancy) ou à la main (Nantes), éventuellement après un cycle de congélation-décongélation destiné à faciliter le décrochement des bactéries (Theix).

Pour étudier les synthèses microbiennes ou établir des bilans de fermentation, il est impératif d'effectuer les dosages sur tous les compartiments des réacteurs, y compris sur les contenus

Tableau I. Effets de la taille des mailles des sachets $(25$ à $250 \mu \mathrm{m})$ sur la fermentation en Rusitec d'une paille : taux de disparition de la matière sèche (TDMS), production d'acides gras volatils totaux (AGVT) et proportion molaire des différents acides gras volatils (Toulouse).

\begin{tabular}{lrrrr}
\hline Taille des mailles $(\mu \mathrm{m})$ & 25 & 46 & 150 & 250 \\
\hline TDMS & 22,1 & 25,3 & 29,4 & 31,6 \\
AGVT mmol & 20,4 & 26,8 & 32,7 & 44,7 \\
C2 \% mol. & 58,7 & 63,4 & 65,9 & 72,6 \\
C3 \% mol. & 34,2 & 29,1 & 26,3 & 22,0 \\
C4 \% mol. & 7,1 & 7,5 & 7,8 & 5,4 \\
\hline
\end{tabular}

Tableau II. Principales caractéristiques des méthodes employées dans les différents centres.

\begin{tabular}{lccccc}
\hline Caractéristiques & Jouy & Nancy & Nantes & Theix & Toulouse \\
\hline Sachets & & & & & \\
$\quad$ Porosité $(\mu \mathrm{m})$ & 150 & 50 & 145 & 45 & 150 \\
P/S a $\left(\mathrm{mg} / \mathrm{cm}^{2}\right)$ & 60 & 60 & 60 & 70 & 30 à 60 \\
& & & & & \\
Substrat & 15,0 & 11,2 & 15,0 & 15,0 & $\leq 24,0$ \\
$\quad$ Poids $(\mathrm{g} / \mathrm{l}$ milieu) & 15,0 & 19,0 & 23,0 & 21,0 & $\leq 27,0$ \\
Poids (g/l sol. sal.) & & & & & \\
Solution Tampon & 100 & 65 & 65 & 70 & 90 \\
$\quad$ Taux de renouvellement $(\% \mathrm{j}-1)$ & & & & & \\
\hline
\end{tabular}

a Poids d'aliment/surface d'échange du sachet. 
des sachets. Dans ces conditions il n'est pas possible de laver les sachets, sous peine de perdre dans les eaux de lavage des microorganismes et des substances dissoutes. Des tissus à larges mailles (145 ou $150 \mu \mathrm{m}$ ) sont alors souvent prétérés parce qu'ils sont plus favorables aux échanges (micro-organismes, liquides, gaz) entre l'intérieur des sachets et le milieu de fermentation. Avec ce type de mailles, l'équipe de Jouy a montré qu'après le rinçage routinier par la solution tampon, la matière organique microbienne résiduelle n'occasionnait qu'une faible sous-évaluation du taux de disparition de la matière organique alimentaire (3 points).

En Rusitec, le rapport "poids de substrat/ surface d'échange"* $(P / S)$ est déterminé par plusieurs paramètres :

- la nécessité de fournir à l'inoculum suffisamment de substrat dégradable pour permettre son maintien en activité normale;

- la taille des sachets, qui dépend de la capacité des réacteurs;

- lencombrement des aliments, qui peut limiter la quantité mise dans chaque sachet.

Czerkawski et Breckenridge (1977) ont montré que le taux de disparition de la matière sèche n'était pas modifié lorsque $P / S$ varie entre 25 et $50 \mathrm{mg} / \mathrm{cm}^{2}$ et l'équipe de Jouy a signalé qu'une augmentation de $P / S$ de 60 à $86 \mathrm{mg} / \mathrm{cm}^{2}$ s'accompagne d'une diminution du taux de disparition de la matière sèche ( 40 contre $56 \%)$, la quantité fermentée restant constante $(8,8$ contre $8,4 \mathrm{~g})$.

A partir de ces résultats, le rapport $P / S$ a été fixé à $60 \mathrm{mg} / \mathrm{cm}^{2}$ à Jouy, à Nancy et à Nantes. A Theix il est de $70 \mathrm{mg} / \mathrm{cm}^{2}$ et à Toulouse il varie de 30 à $60 \mathrm{mg} / \mathrm{cm}^{2}$ en fonction de l'encombrement de l'aliment (Tableau II). Dans tous les cas ce rapport est supérieur à celui préconisé dans la méthode des sachets in situ.

\section{Solution tampon}

La composition de la solution saline utilisée (Tableau III) dérive de celle de Tisserand et Zelter (1965), elle même adaptée pour les macro- éléments, de la solution de McDougall (1948). La composition en macro-éléments de cette solution tampon diffère peu de celle utilisée par Czerkawski et Breckenridge (1977). Elle contient seulement un peu moins de phosphate $(7,12$ contre $9,3 \mathrm{~g} / \mathrm{l})$. Par contre, elle est plus concentrée que la solution utilisée par Merry at al. (1987) qui diluent le tampon de McDougall avec de l'eau (60/40). Cette dilution devrait permettre de mieux simuler les effets des aliments concentrés sur le pH du milieu. En effet, le pouvoir tampon de la solution utilisée par les auteurs est très élevé, ce qui atténue les variations du $\mathrm{pH}$. Les modifications apportées sont destinées à augmenter l'apport de soufre et à fournir de l'azote facilement dégradable. Les apports optimaux de soufre et d'azote ne sont pas encore évalués avec certitude. Ils doivent être fonction de la concentration et de la dégradabilité de ces éléments dans les aliments. Ils doivent probablement satisfaire aux recommandations (in vivo) de Durand (1987), selon lesquelles la disponibilité en azote doit être de $\mathbf{4 0} \mathrm{g}$ par $\mathrm{kg}$ de matière organique apparemment dégradable dans le rumen, avec un rapport «azote disponible/soufre disponible" d'environ 10.

Czerkawski et Breckenridge (1977) comparent différents taux de renouvellement (de 0,35 à $0,97 /$ ) ) avec un substrat mixte. Des taux allant de 0,75 à $1,0 /$ leur semblent le mieux correspondre aux conditions de milieu in vivo (concentrations en AGV). Dans des expériences ultérieures, de Wallace et al. (1980), Wallace et al. (1981) et Czerkawski et Breckenridge (1985), des taux de renouvellement compris entre 0,75 et $0,9 / j$ ont été utilisés. Stanier et Davies (1981) observent qu'une réduction du taux de renouvellement de 0,9 à $0,45 /$ j augmente la production de gaz, réduit celle d'AGV avec une augmentation de la proportion d'acétate et diminue le rendement de la protéosynthèse qui passe de 14,2 à $8,1 \mathrm{~g}$ d'azote microbien par $\mathrm{kg}$ de matière organique disparue des sachets. Des taux de renouvellement supérieurs à $1 / j$ sont pratiqués aux USA. Schaetzel et Johnson (1981) considèrent qu'un taux de 2,28/j est plus favorable que $1,15 / \mathrm{j}$ pour la production d'AGV. Cependant, leurs conditions de travail sont différentes de celles de Czerkawski pour les quantités de substrat $(25 \mathrm{~g} / \mathrm{j})$ et la composition de la solution tampon. En France, le groupe de Nantes a montré

\footnotetext{
* La surface d'échange est la surface totale des sachets qui correspond aux possibilités d'échanges entre l'intérieur et l'extérieur des sachets.
} 
Tableau III. Composition de la solution tampon.

$\begin{array}{ll}\text { Macro éléments } & \begin{array}{l}\text { Oligo éléments } \\ (\mathrm{g} / \mathrm{l})\end{array}\end{array}$

\begin{tabular}{lllr}
\hline $\mathrm{NaHCO}_{3}$ & 9,240 & $\mathrm{FeSO}_{4}, 7 \mathrm{H}_{2} \mathrm{O}$ & 36,80 \\
$\mathrm{Na}_{2} \mathrm{HPO}_{4}, 12 \mathrm{H}_{2} \mathrm{O}$ & 7,125 & $\mathrm{MnSO}_{4}, \mathrm{H}_{2} \mathrm{O}$ & 19,00 \\
$\mathrm{NaCl}$ & 0,470 & $\mathrm{ZnSO}_{4}, 7 \mathrm{H}_{2} \mathrm{O}$ & 4,40 \\
$\mathrm{KCl}$ & 0,450 & $\mathrm{CoCl}_{2}, 6 \mathrm{H}_{2} \mathrm{O}$ & 1,20 \\
$\mathrm{CaCl}_{2}$ anhydre & 0,055 & $\mathrm{CuSO}_{4}, 5 \mathrm{H}_{2} \mathrm{O}$ & 0,98 \\
$\mathrm{MgCl}_{2}$ anhydre & 0,047 & $\mathrm{Mo}_{7}\left(\mathrm{NH}_{4}\right)_{6} \mathrm{O}_{24}, 4 \mathrm{H}_{2} \mathrm{O}$ & 0,17 \\
\hline
\end{tabular}

N.B. : $\mathrm{Du} \mathrm{Na} \mathrm{SO}_{4}$ est ajouté en fonction de l'apport de $\mathrm{S}$ dans le substrat.

que le taux de disparition de la matière sèche augmente $(74,2 \pm 1,34$ contre $67,6 \pm 4,17)$ quand le taux de renouvellement de la phase liquide passe de 0,65 à $1,0 / \mathrm{j}$. Une étude très complète du groupe de Theix a caractérisé les effets d'une augmentation du taux de renouvellement, entre 0,29 et $5,3 / \mathrm{j}$. Cette augmentation aboutit à une plus forte efficacité (azote bactérien/matière organique fermentée) de la protéosynthèse par les bactéries libres du réacteur : elle est pratiquement doublée entre 0,29 et $2,4 \pi$ ou entre 0,34 et $4,0 / j$. Parallèlement, le $\mathrm{pH}$ du milieu augmente et le taux de disparition des composants pariétaux diminue. Enfin, l'augmentation du taux de renouvellement accélère la disparition des protozoaires du fermenteur.

Le taux de renouvellement de la phase liquide n'est pas le même dans les difterentes équipes : $0,65 / \mathrm{j}$ à Nancy et à Nantes, $0,7 / \mathrm{j}$ à Theix, $0,9 / \mathrm{j}$ à Toulouse et $1,0 / \mathrm{j}$ à Jouy (Tableau II). II est toujours plus faible $(1,6 / \mathrm{j}$ selon Komisarczuk, 1985) que celui appliqué dans le système à flux continu de Hoover et al. (1976), beaucoup plus proche des valeurs mesurées in vivo.

\section{Substrats}

Le poids de substrat introduit quotidiennement est constant, sauf lorsque l'aliment est trop encombrant. Exprimé par rapport au volume du milieu de fermentation, il est de 11,2 $\mathrm{g} / \mathrm{a}$ Nancy, de $15 \mathrm{~g} / \mathrm{l}$ à Jouy, à Nantes et à Theix, et varie de 12 à $24 \mathrm{~g} / \mathrm{l}$ à Toulouse. Rapportés à la quantité de solution tampon infusée ces poids de substrat correspondent à $15 \mathrm{~g} / \mathrm{l}$ à Jouy, $19 \mathrm{~g} / \mathrm{l}$ à Nancy, $21 \mathrm{~g} / \mathrm{l}$ à Theix, $23 \mathrm{~g} / \mathrm{a}$ Nantes et $13 \mathrm{a}$ $27 \mathrm{~g} / \mathrm{l}$ à Toulouse. Malgré la grande différence de taux de renouvellement de la phase liquide, ces valeurs sont assez proches de celle retenue dans le système à flux continu (22 g par litre de solution tampon).

Le plus souvent, les équipes essaient d'utiliser les aliments sans leur faire subir de traitement préalable. Cependant, dans le cas de fourrages longs il est nécessaire de réduire la taille des particules. A Theix et à Toulouse, les foins et les pailles sont coupés en brins courts (quelques $\mathrm{cm}$ et 0,5 à $1 \mathrm{~cm}$ respectivement); à Nancy, ils sont broyés à la grille de $1,7 \mathrm{~mm}$ et à Jouy à $3 \mathrm{~mm}$. A Nantes, les substrats autres que les fourrages sont broyés à $2 \mathrm{~mm}$. Le traitement par la chaleur étant susceptible de nuire aux fermentations, les aliments humides sont lyophilisés avant utilisation.

\section{Conservation des effluents}

Les effluents sont conservés par du chlorure mercurique, éventuellement additionné d'acide phosphorique (Nancy), sauf si des dosages enzymatiques doivent être pratiqués; dans ce cas, 
les effluents sont acidifiés avec de l'acide sulfurique. De plus, à Jouy et à Theix les récipients où sont recueillis les effluents sont placés dans un bain-marie à $4{ }^{\circ} \mathrm{C}$ et à Toulouse des cristaux de thymol sont placés dans le tube séparateur de phases.

\section{Pratique des mesures en cinétique}

L'étude cinétique de l'apparition de substances solubles est pratiquée sur des échantillons prélevés soit dans la phase liquide du réacteur soit dans les effluents.

Pour l'étude des solides, les techniques diffèrent selon les centres :

- à Toulouse, 3 sachets sont présents en permanence dans chaque réacteur. Ils sont renouvelés par paire de manière à recueillir quotidiennement un sachet ayant séjourné $24 \mathrm{~h}$ et un sachet ayant séjourné $48 \mathrm{~h}$ dans le réacteur.

- à Theix, des essais de cinétique ont été effectués de la même manière, avec des durées de séjour de 24,48 et $96 \mathrm{~h}$ pour les pailles.

- à Nancy, chaque réacteur contient en permanence 4 sachets qui sont renouvelés par paire. Les études de cinétiques se pratiquent habituellement à $4,12,24$ et 48 h. Deux sachets sont remplacés après la durée de fermentation désirée et le rythme de routine est repris pendant $2 \mathrm{j}$ avant la mesure suivante.

\section{PARAMĖTRES ÉTUDIÉS}

\section{Dégradation des substrats}

Le taux de disparition de la matière sèche est mesuré pour une durée de fermentation de $48 \mathrm{~h}$, durée normale de séjour des sachets dans le Rusitec. Pour 98 mesures portant sur 30 aliments différents, la variabilité entre jours du taux de disparition en
$48 \mathrm{~h}$ de la matière sèche, exprimée par le coefficient de variation ( $C V=$ écart type $x$ $100 /$ moyenne) est comprise entre 1,2 et $29,7 \%$ selon les aliments (une valeur accidentelle à $50,7 \%$ ). Elle est en moyenne de $8,8 \%$ et $2 / 3$ des mesures donnent des coefficients de variation inférieurs à $10 \%$ (Fig. 3). Cette variabilité journalière impose de calculer une moyenne sur plusieurs jours du taux de disparition de la matière sèche pour pouvoir donner une valeur suffisamment précise.

Pour un même aliment, la moyenne sur plusieurs jours ( 3 à 5 ) du taux de disparition de la matière sèche est très peu différente entre 2 réacteurs. Sur 13 aliments, l'écart entre la valeur la plus forte et la valeur la plus faible a été en moyenne de 1,55 point.

Lorsque la fermentation se produit dans des conditions défavorables, spécialement lorsque la teneur du milieu de fermentation en ammoniac est trop faible, le taux de disparition de la matière sèche est réduit. $\mathrm{Pa}$ rallèlement les écarts entre réacteurs et la

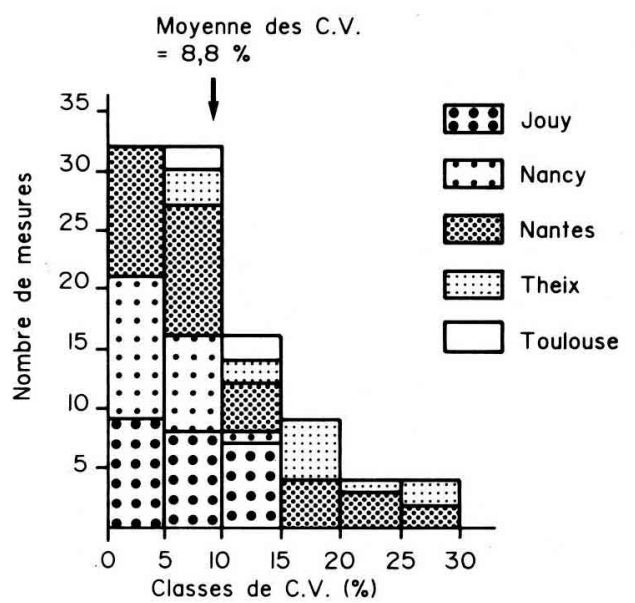

Fig. 3. Diagramme de répartition des mesures de taux de disparition de la matière sèche en fonction du coefficient de variation entre jours. 
variabilité entre jours peuvent être considérablement accrus.

D'une manière générale nous considérons qu'une mesure du taux de disparition de la matière sèche dans 2 réacteurs pendant $4 \mathrm{j}$ fournit une précision satisfaisante (coefficient de variation entre mesures d'environ $3 \%$ en moyenne).

Des comparaisons entre les taux de disparition de la matière sèche ainsi obtenus et ceux mesurés in situ par la méthode des sachets ont été effectuées à Nancy (12 aliments) et à Nantes (9 aliments). Dans l'ensemble, les 2 méthodes fournissent des résultats très proches (Fig. 4). Cependant, les valeurs mesurées en Rusitec sont souvent un peu plus faibles que celles obtenues in situ.

Le taux de disparition en $48 \mathrm{~h}$ de la matière organique est le plus souvent très proche de celui de la matière sèche. Ses variabilités entre réacteurs et entre jours sont du même ordre que celles obtenues dans le cas de la matière sèche. La comparaison entre les résultats obtenus en Rusitec et in situ permet de tirer les

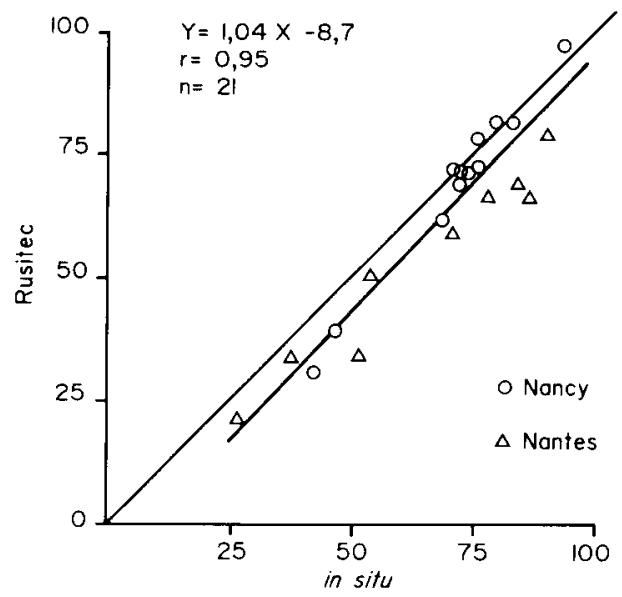

Fig. 4. Relation entre les taux de disparition de la matière sèche en $48 \mathrm{~h}$ mesurés en Rusitec et in situ (méthode des sachets). mêmes conclusions que pour le taux de disparition de la matière sèche.

La variabilité journalière des taux de disparition des composants de la matière sèche, et spécialement des composants pariétaux, est rarement étudiée parce qu'elle nécessite l'analyse jour par jour des résidus de fermentation. Cette opération est souvent impossible à réaliser, faute de disposer de quantités suffisantes de résidus. L'équipe de Nancy, qui utilise des réacteurs de plus grande capacité, et celle de Toulouse, ont pu pratiquer cette étude sur le taux de disparition des parois cellulaires (NDF de Goering \& van Soest, 1970) sur un petit nombre d'aliments. La variabilité entre jours du taux de disparition de la fraction NDF, exprimée par son coefficient de variation, est généralement un peu plus forte que celle calculée dans le cas des taux de disparition de la matière sèche mais le plus souvent comprise entre 1 et $15 \%$. Elle est accrue par les variations dues à la méthode de dosage de la fraction NDF et probablement aussi par celles qui sont dues aux effets du séchage des résidus alimentaires sur leur résistance au détergent. Les résultats obtenus dans 2 réacteurs différents (moyennes sur $4 \mathrm{j}$ ) sont très proches.

Des résultats analogues ont été trouvés par l'équipe de Nantes pour les taux de disparition des fractions NDF et ADF ainsi que pour les fractions hémicellulosique et cellulosique selon van Soest, bien que les analyses aient été pratiquées sur des mélanges des résidus de fermentation par périodes de $5 \mathrm{j}$. Là encore, la variabilité doit être due, au moins en partie, à la méthode de dosage. En effet, le dosage des oses neutres des hémicelluloses et de la cellulose par chromatographie en phase gazeuse donne généralement une variabilité des taux de disparition de ces fractions plus faible que celle calculée à partir des résultats fournis par la méthode de van 
Soest : de 0,4 à $15 \%$ contre 2 à $25 \%$ pour les hémicelluloses et de 2 à $18 \%$ contre 4 à $28 \%$ pour la cellulose.

Les résultats obtenus à Nantes montrent la bonne similitude des résultats obtenus en Rusitec et de ceux obtenus in situ (Fig. 5). Tout comme dans le cas de la méthode des sachets in situ, la mesure en Rusitec du taux de disparition de l'azote et de ses différentes fractions impose d'obtenir des résidus de fermentation indemnes de corps microbiens, ce qui nécessite, au minimum, un lavage efficace des sachets.

Selon les résultats obtenus à Nancy et à Theix, les variabilités entre jours et entre réacteurs du taux de disparition de l'azote sont du même ordre de grandeur que celles calculées pour la matière sèche, et le plus souvent inférieures à $10 \%$.

Sur 23 aliments, le taux de disparition en $48 \mathrm{~h}$ de l'azote a été mesuré parallèlement en Rusitec et in situ par l'équipe de Nancy (Fig. 6). Pour la plupart de ces aliments, la différence entre les 2 méthodes est peu importante, même si la teneur en azote ammoniacal du milieu de fermentation à laquelle aboutit la dégradation des matières azotées en Rusitec est très faible. Parmi les aliments testés, seules les pulpes de betteraves, le maïs déshydraté et le résidu de pressage du raisin, dont la fermentation aboutit à des teneurs en azote ammoniacal du milieu, inférieures à $1 \mathrm{mg} / 100 \mathrm{ml}$, ont des taux de disparition de l'azote nettement plus faibles en Rusitec qu'in situ.

La cinétique de disparition de l'azote de 11 aliments a été mesurée en Rusitec et en sachets in situ. II semble que la dégradation pour des durées de fermentation courtes ( 2 ou 4 h) ou au contraire pour de longues durées ( $48 \mathrm{~h}$ ) soit peu différente d'une méthode à l'autre. En revanche, aux temps intermédiaires, la différence entre les 2 méthodes s'accroitt. II est probable que les dégradations en des temps courts ou en des temps longs de fermentation sont surtout déterminées par des caractères propres aux aliments (solubilité, complexes entre les protéines et la lignine ou les polysaccharides) mais que la vitesse de fermentation de la fraction lentement dégradable des matières azotées dépend surtout de l'activité des micro-organismes. In vitro, le rythme d'alimentation d'un "repas" par jour ne serait pas favorable à l'activité fermentaire entre 4 et 24 h d'incubation, alors qu'in vivo le deuxième repas de la journée permettrait aux microorganismes de reprendre une activité efficace.

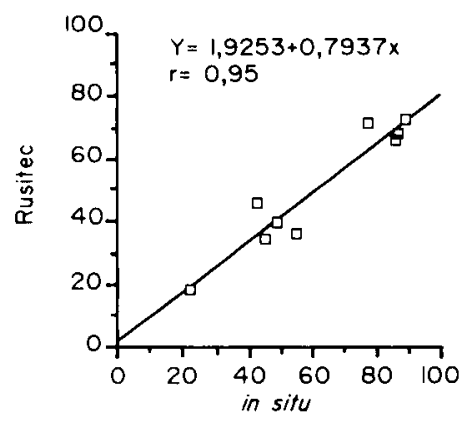

Fig. 5. Relation entre les taux de disparition des composants pariétaux (dosés par chromatographie en phase gazeuse) en $48 \mathrm{~h}$ en Rusitec et in situ par la méthode des sachets (Nantes) : (a) hemicellulose; (b) cellulose. 


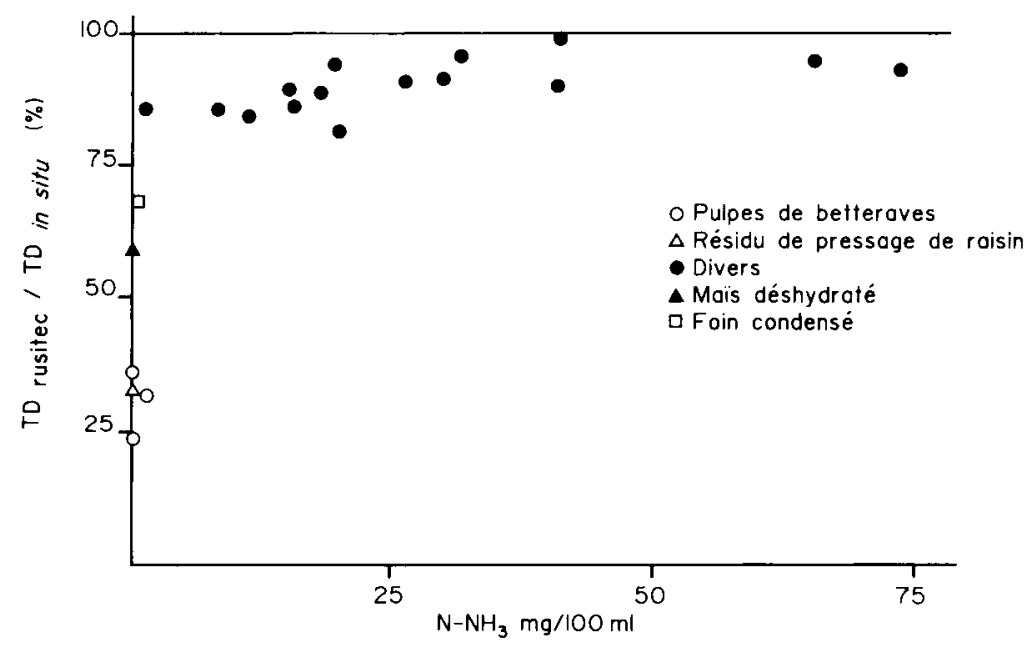

Fig. 6. Variation du taux de disparition de l'azote total en $48 \mathrm{~h}$ en Rusitec, exprimé en \% de la disparition en $48 \mathrm{~h}$ in situ par la méthode des sachets, en fonction de la teneur du milieu in vitro en azote ammoniacal, pour différents aliments (Nancy).

\section{Faciès fermentaire}

Les teneurs en acides gras volatils (AGV) peuvent être mesurées à l'intérieur du réacteur. Cette mesure permet de décrire le faciès fermentaire en cinétique. Pour mesurer les quantités d'AGV produites, il est nécessaire de doser les AGV dans les effluents, ce qui, en revanche, ne fournit qu'une valeur cumulée des concentrations en AGV. C'est surtout cette dernière méthode qui est pratiquée.

La variabilité journalière de la concentration dans les effluents des AGV totaux et de la quantité d'AGV totaux produite en $24 \mathrm{~h}$ est généralement assez élevée : en moyenne, le coefficient de variation est de $11,4 \%$ sur les mesures pratiquées à Nantes ( 1,6 à $24,5 \%$ selon les aliments) et de $7,1 \%(3,4$ à $11,0 \%$ selon les aliments) sur celles pratiquées à Jouy. Au contraire, les pourcentages des différents acides, spécialement du $\mathrm{C}_{2}$ et du $\mathrm{C}_{3}$, varient peu d'un jour à l'autre (coefficients de variation égaux à 2,1 et $4,7 \%$ respectivement). Les combinaisons faites entre les concentrations des différents AGV, en particulier le rapport "acide acétique/acide propionique", sont elles aussi assez peu variables entre jours. A Theix, pour 8 séries de mesures différant par la vitesse de renouvellement de la phase liquide, sur une luzerne déshydratée, la variabilité entre jours (coefficient de variations) de ce rapport est en moyenne de $14,2 \%$ et reste comprise entre 0,7 et $27,5 \%$ ( 8 j de mesures par série). Des variabilités plus faibles sont signalées par l'équipe de Toulouse pour un foin $(6,5 \%)$ et pour une paille traitée à la soude $(9,2 \%)$.

Les résultats obtenus à Jouy et à Nantes ont montré que la quantité théorique de matière organique fermentée (MOF) calculée à partir des quantités des différents AGV produits 
$\mathrm{MOF}=\left(\mathrm{C}_{2} / 2+\mathrm{C}_{3} / 2+\mathrm{C}_{4}+\mathrm{iC}_{4}+\mathrm{C}_{5}+\mathrm{iC}_{5}\right)$ $\times 162$

est étroitement corrélée à la quantité de matière organique disparue des sachets (MODS). La relation obtenue est peu différente entre ces 2 séries de résultats (Fig. 7). La MOF ne tient pas compte de la matière organique du substrat incorporée dans les micro-organismes et correspond à la mesure in vivo de la matière organique apparemment digérée dans le rumen. La MODS est plus proche de la matière organique réellement dégradée, les résidus de matière organique d'origine microbienne étant faibles par rapport aux résidus alimentaires (pp. 291-293). Ainsi, plus un substrat stimule la production de biomasse microbienne dans l'effluent, plus le rapport MOF/MODS a tendance à s'abaisser (Durand et al., 1988). En outre, avec certains aliments particuliers, on ne peut pas exclure que soient perdus des sachets des particules non fermentées ultérieurement (Morrisson \& Brice, 1984), ce qui ris- que également d'accentuer la différence entre MOF et MODS. Le potentiel de dégradation d'un substrat donné est ainsi estimé avec une meilleure précision lorsqu'on associe les 2 critères MOF et MODS.

La quantité et la composition du mélange d'AGV produits en Rusitec ne peuvent pas être comparées aux valeurs correspondantes in vivo, les AGV étant absorbés au cours de leur production. Cependant, à partir de 6 essais de comparaison des produits de la fermentation, le groupe de Theix constate que la proportion molaire du propionate est systématiquement plus forte en Rusitec que dans le rumen, alors que les proportions d'acétate et de butyrate sont, au contraire, plus faibles (Tableau IV). Ce résultat peut s'expliquer, pour le propionate et l'acétate, par des vitesses relatives d'absorption différentes, mais pas pour le butyrate, qui est l'acide le plus rapidement absorbé dans le rumen (Stevens, 1970), alors que sa quantité y est plus importante qu'en Rusitec.

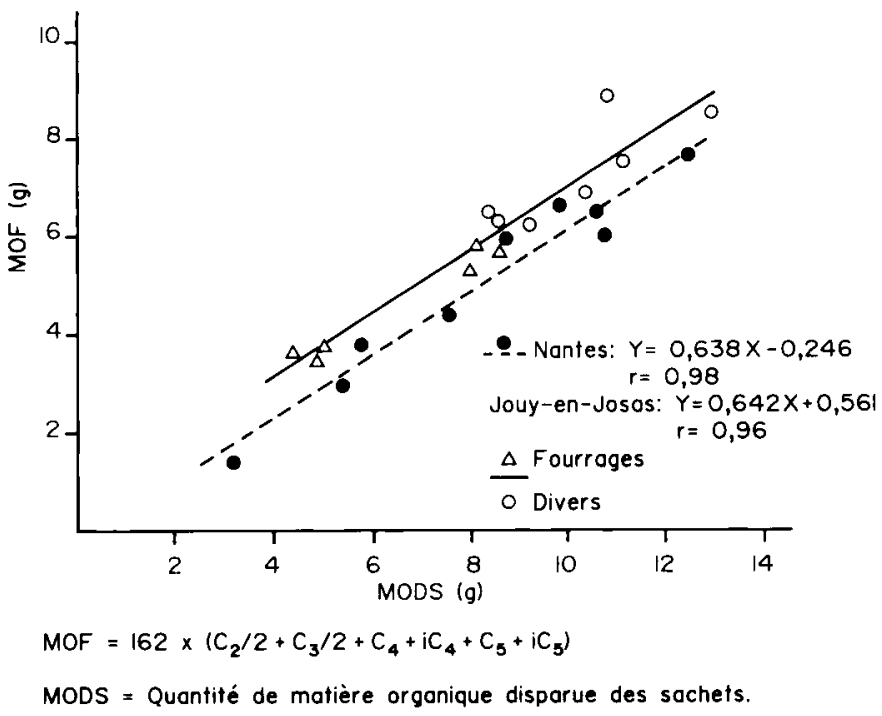

Fig. 7. Relation entre la quantité de matière organique fermentée thérique (MOF) et la quantité de matière organique disparue des sachets (MODS), en Rusitec. 
Le volume des gaz produits varie beaucoup d'un jour à l'autre (Tableau V). Cependant, la composition du mélange gazeux exprimée par la proportion de méthane dans le mélange $\left(\mathrm{CH}_{4} /\left(\mathrm{CO}_{2}\right.\right.$ $\left.+\mathrm{CH}_{4}\right)$ ) paraît beaucoup plus stable. $\mathrm{A}$ Jouy, des mesures sur 7 aliments donnent des coefficients de variation de ce paramètre compris entre 2,4 et $6,7 \%(4,6 \%$ en moyenne). Pour le groupe de Theix, le rapport $\mathrm{CH}_{4} /\left(\mathrm{CO}_{2}+\mathrm{CH}_{4}\right)$ serait plus faible en Rusitec que dans le rumen. La diffé- rence proviendrait plutôt d'une production excessive de $\mathrm{CO}_{2}$ en Rusitec, due à la quantité importante de carbonate monosodique perfusée, que de modifications qualitatives de la population microbienne.

La teneur en azote ammoniacal peut être mesurée à l'intérieur des réacteurs afin de savoir si la disponibilité en azote est suffisante pour permettre une activité normale des micro-organismes. De telles mesures peuvent être effectuées en cinétique sur $24 \mathrm{~h}$ et les variations de la teneur

Tableau IV. Ecart relatif (en p. 100) des paramètres fermentaires mesurés en Rusitec (taux de renouvellement : $0,7 /$ ) par rapport aux mesures effectuées in vivo (moutons) (Theix).

\begin{tabular}{|c|c|c|c|c|c|c|c|}
\hline Expérience & 1 & & & 3 & 4 & 5 & 6 \\
\hline Substrat & $\begin{array}{l}\text { Foin } \\
\text { Mani } \\
\text { T. de }\end{array}$ & & $\begin{array}{l}70 \% \\
20 \% \\
10 \%\end{array}$ & & $\begin{array}{l}\text { Paille } \\
\text { non } \\
\text { traitée }\end{array}$ & $\begin{array}{l}\text { Paille } \\
\text { traitée } \\
\mathrm{NH} 3\end{array}$ & $\begin{array}{c}\text { Paille } \\
\text { traitée } \\
\mathrm{NaOH}\end{array}$ \\
\hline $\begin{array}{l}\text { AGV (mmol/) } \\
\text { dont C2 p. } 100 \\
\text { C3 p. } 100 \\
\text { C4 p. } 100 \\
\text { IC4 + IC5 p. } 100 \\
\text { C5 p. } 100 \\
\text { C2/C2 + C3 }\end{array}$ & $\begin{array}{l}+12,4 \\
-8,3^{*} \\
+48,9^{* *} \\
-18,4^{*} \\
+25,9^{*} \\
+58,3^{*} \\
-8,7^{*}\end{array}$ & $\begin{array}{l}- \\
-1 \\
+4 \\
-1 \\
+2 \\
+7 \\
-1\end{array}$ & $\begin{array}{l}1 \\
5 * \\
4^{* *} \\
2^{*} \\
2^{*} \\
1^{*} \\
4^{*}\end{array}$ & $\begin{array}{l}-20,7^{*} \\
-14,4^{*} \\
+33,9^{* *} \\
-15,3^{*} \\
+45.8^{* *} \\
+89,8^{*} \\
-8,2^{*}\end{array}$ & $\begin{array}{l}-8,1 \\
-5,7 \\
+26,0^{* *} \\
-23,0^{* *} \\
+21.3 \\
+37,2^{*} \\
-7,5^{*}\end{array}$ & $\begin{array}{l}-2,9 \\
-6,7 \\
+27,3^{* *} \\
-15,6^{*} \\
+20,0^{*} \\
+12,8^{*} \\
-6,7^{*}\end{array}$ & $\begin{array}{l}-3,8 \\
-5,5 \\
+11,0^{*} \\
-9,3^{*} \\
+16,9^{*} \\
+21,7^{*} \\
-2,3\end{array}$ \\
\hline
\end{tabular}

* Effet significatif à $P<0,05$.

** Effet significatif a $P<0,01$.

Tableau V. Variabilité entre jours du volume de gaz produit en Rusitec dans les différentes stations.

\begin{tabular}{lcccc}
\hline & & \multicolumn{3}{c}{ Coefficient de variations } \\
\cline { 3 - 5 } Station & $\begin{array}{c}\text { Nombre } \\
\text { de } \\
\text { mesures }\end{array}$ & Moyenne & Minimum & Maximum \\
\cline { 3 - 5 } & & & & \\
Jouy & 20 & 16,1 & 4,0 & 37,0 \\
Nancy & 9 & 10,7 & 4,1 & 26,1 \\
Theix & 9 & 38,1 & 10,8 & 90,9 \\
Toulouse & 2 & 14,8 & 9,5 & 20,0 \\
\hline
\end{tabular}


en $\mathrm{N}-\mathrm{NH}_{3}$ résultent de l'ensemble des activités de dégradation et de synthèse des micro-organismes. La valeur obtenue avant l'approvisionnement des réacteurs peut être considérée comme le niveau de base de la concentration en $\mathrm{N}-\mathrm{NH}_{3}$. Elle est assez étroitement liée à la teneur en matières azotées totales des aliments : $\mathrm{N}-\mathrm{NH}_{3}=1,57 \mathrm{MAT}-11,8 ; r=0,90$ et $n=$ $13\left(\mathrm{~N}-\mathrm{NH}_{3}\right.$ en $\mathrm{mg} / 100 \mathrm{ml}$ et MAT en $\%$ de MS). Pour de nombreux aliments, elle est supérieure à 4 ou $5 \mathrm{mg} / 100 \mathrm{ml}$. Avec certains aliments pauvres en azote (pulpes de betteraves, foins de mauvaise qualité, pailles, maïs plante entière déshydraté ou ensilé) et si la solution tampon n'est pas supplémentée en urée, cette teneur est très faible, parfois à la limite des concentrations mesurables par les techniques habituelles (méthode de Conway ou potentiométrie). La correspondance entre la teneur en $\mathrm{N}-\mathrm{NH}_{3}$ de la phase liquide et celle de la phase intermédiaire, c'est-à-dire à proximité immédiate des activités microbiennes les plus fortes, n'a, à notre connaissance, jamais été étudiée.

Pour 8 mesures de 5 à 15 j effectuées à Nancy sur 5 aliments différents, la variabilité de la teneur en $\mathrm{N}-\mathrm{NH}_{3}$ du milieu avant approvisionnement est en moyenne de $13,6 \%(C V=6,5$ à, $21,0 \%$ selon la mesure).

A Jouy, dans certains essais, l'adénosine triphosphate est dosée dans les différents compartiments du Rusitec et sert à caractériser l'activité microbienne (Komisarczuk et al., 1987b).

\section{Protéosynthèse}

Plusieurs auteurs considèrent que l'azote précipitable (par l'acide trichloracétique ou par l'acide tungstique) retrouvé dans l'effluent représente l'azote d'origine microbi- enne (Fuller \& Johnson, 1981; Schaetzel \& Johnson, 1981). Ces auteurs supposent qu'aucun contaminant protéique d'origine alimentaire ne peut se trouver dans les effluents. D'autres estiment la biomasse microbienne libre par le culot de centrifugation fractionnée des effluents (Guy et al., 1988; Ramihone et al., 1988). La biomasse microbienne adhérente est parfois estimée par le culot de centrifugation fractionnée de la phase liquide obtenue après traitement au "stomacher" des résidus des sachets selon Merry et McAllan (1983) et Guy et al. (1988). Ces critières ne sont qu'indicatifs et lorsque les substrats contiennent des protéines il est nécessaire de recourir à des marqueurs de protéosynthèse microbienne pour estimer la production d'azote microbien. Les principes et les aléas sont les mêmes que pour les mesures in vivo à la sortie du rumen.

Czerkawski et Breckenridge (1977, $1979 a, b, 1982,1985)$ et Wallace et al. (1980) déterminent la production de matière sèche microbienne à partir des acides diaminopimélique (DAP) et aminoéthylphosphonique (AEP), respectivement pour les bactéries et pour les protozoaires. Ces analyses sont effectuées sur les résidus des sachets et dans la matière sèche des effluents. L'ARN est utilisé comme marqueur en fermenteur à flux continu (Komisarczuk et al., 1987) et peut l'être également en Rusitec (Durand et al., 1986c). Cependant, les acides nucléiques alimentaires peuvent ne pas être dégradés en totalité et faussent la détermination de l'azote microbien dans les résidus des sachets. Avec le substrat «Son», Durand et al. (1986b) ont observé cette contamination (Tableau VI) et ont estimé comme Smith et al. (1978) que 15\% de l'ARN alimentaire n'avaient pas été dégradés. De même le groupe de Nancy a obtenu de meilleurs résultats avec le DAP qu'avec I'ARN (Tableau VII). 
Tableau VI. Production d'azote microbien selon la nature du substrat (Jouy-en-Josas).

\begin{tabular}{|c|c|c|c|c|c|}
\hline \multirow{2}{*}{ Substrats } & \multirow{2}{*}{$\begin{array}{l}\text { Sachet } \\
\text { seul } \\
(\% \text { du } \\
\text { total) }\end{array}$} & \multicolumn{4}{|c|}{ Total (sachet + effluents) } \\
\hline & & $m g N / j$ & $m g N / g M S$ & $m g ~ N / g ~ M O F$ & $m g ~ N / g M O D_{s}$ \\
\hline Aliment purifié Ra & 11 & 187 & 11,9 & 20,7 & 14,9 \\
\hline Aliment mixte $1 \mathrm{Ra}$ & 21 & $179 \pm 9$ & $11,9 \pm 0,6$ & $23,5 \pm 1,2$ & $17,7 \pm 0,9$ \\
\hline Aliment mixte $2 \mathrm{Na}$ & 31 & $150 \pm 3$ & $9,3 \pm 0,2$ & $24,0 \pm 0,5$ & $17,6 \pm 0,3$ \\
\hline Pulpes de betteraves ${ }^{A}$ & 42 & $155 \pm 20$ & $10,0 \pm 1,3$ & $17,9 \pm 2$ & $14,6 \pm 1,9$ \\
\hline Son de blé ${ }^{R}$ & $26 *$ & 142 & 9,3 & 22,9 & 15,5 \\
\hline Paille sodée $N$ & $50^{*}$ & $130 \pm 2$ & $8,2 \pm 0,1$ & $23,4 \pm 0,5$ & $15,1 \pm 0,2$ \\
\hline Paille non traitée ${ }^{N}$ & 59 & $86 \pm 2$ & $5,4 \pm 0,1$ & $25,4 \pm 1,1$ & $17,6 \pm 0,3$ \\
\hline
\end{tabular}

$\mathrm{R}:$ Marqueur ARN; ${ }^{\mathrm{N}}$ : marqueur ${ }^{15} \mathrm{~N}$.

* : Corrigé pour $15 \%$ de l'ARN alimentaire non dégradé.

a : Composition en $p \%$.

aliment purifié : amidon 40 , cellulose 28 , cérélose 24

aliment mixte 1 : manioc 30 , pulpes de betteraves 50 , paille 9 .

aliment mixte 2 : manioc 21 , pulpes de betteraves 29 , paille 50 .

MOF = matière organique fermentescible calculée à partir des AGV.

$M O D_{s}$ = matière organique disparue des sachets.

L'acide désoxyribonucléique (ADN) a été utilisé avec succès par Stanier et Davies (1981), mais seul l'azote microbien des effluents était déterminé.

L'utilisation de $15 \mathrm{~N}$ perfusé sous forme de sels ammoniacaux ou d'urée dans le mélange tampon est une technique très fiable qui a été utilisée par le groupe de Jouy (Komisarczuk et al., 1987a, b) (Tableau VI). Elle permet, en outre, d'estimer : (i) la proportion de l'azote microbien provenant des acides aminés ou des peptides alimentaires, par comparaison entre l'enrichissement spécifique bactérien et celui de $\mathrm{N}-\mathrm{NH}_{3}$; (ii) la proportion de $\mathrm{N}-\mathrm{NH}_{3}$ d'origine alimentaire par comparaison entre l'enrichissement spécifique du $\mathrm{N}$ $\mathrm{NH}_{3}$ et celui de l'urée perfusée.

Quel que soit le marqueur utilisé, il est nécessaire, comme in vivo, de mesurer sa concentration dans un culot bactérien obtenu à partir de la phase liquide (Jouy,
Nancy, Toulouse) et, si possible également à partir de la phase solide (Komisarczuk, 1987a, b). Cependant, les bactéries de la phase solide, dont la composition parait différente de celles de la phase liquide (Merry \& McAllan, 1983; Bauchart et al., 1986; Komisarczuk et al., 1987b), ce qui justifie leur analyse séparée, sont parfois difficiles à détacher des particules de substrat. Lorsque la valeur de la proportion du marqueur mesurée dans les bactéries isolées de l'effluent est appliquée aux résidus des sachets, la production d'azote total microbien peut être sous-évaluée d'environ 10\% (Komisarczuk et al., 1987b).

Le Tableau VI rapporte quelques résultats de production d'azote microbien obtenus avec différents types de substrats par le groupe de Jouy. Une proportion importante de l'azote microbien est retrouvée dans les résidus alimentaires. Cette proportion varie avec les aliments et elle est 
Tableau VII. Cinétique de la production d'azote bactérien $\left(\mathrm{N}_{\text {bacter }}\right)$ en Rusitec et mesure du flux d'azote bactérien dans le duodenum de mouton (Nancy).

Substrat in vitro et régime alimentaire : luzerne deshydratée, limitée in vivo à $900 \mathrm{~g} / \mathrm{j}$

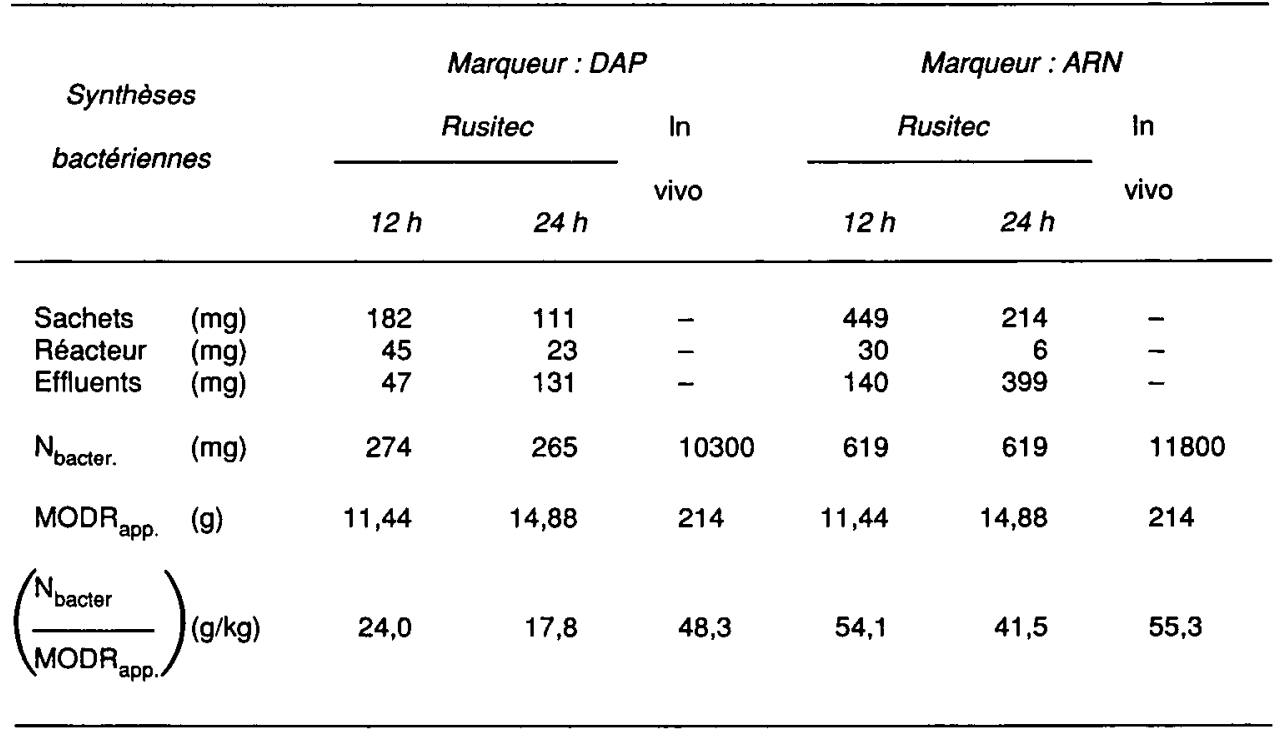

MODR = Matière organique disparue dans le rumen (in vivo) ou disparue des sachets (en Rusitec) : MODR parente, c'est-à-dire sans corriger la matière organique résiduelle de la matière organique bactérienne.

d'autant plus élevée qu'ils sont moins dégradables. Ce résultat est conforme aux observations de Czerkawski et Breckenridge $(1977,1985)$ et de Wallace et al. (1980) qui retrouvent dans les résidus de foins 50 à $60 \%$ de l'azote microbien total contre $38 \%$ avec des aliments mixtes et seulement $26 \%$ avec des concentrés. Aussi, pour une estimation complète de la protéosynthèse bactérienne, il est impératif de mesurer aussi l'azote microbien dans les résidus et de ne pas se limiter aux effluents, comme cela est parfois pratiqué.

L'intensité de la protéosynthèse en Rusitec varie, comme in vivo, avec la dégradabilité de la matière organique de l'ali- ment. Le rendement de la protéosynthèse, exprimé par rapport à la MOF (calculée à partir de la production d'AGV) ou à la MODS (matière organique disparue des sachets) est relativement constant, sauf pour les substrats "purifiés" et les pulpes de betteraves. Ces rendements, voisins de $24 \mathrm{~g} \mathrm{~N} / \mathrm{kg}$ MOF, sont plus faibles que dans le fermenteur à flux continu $(30 \mathrm{~g} \mathrm{~N} / \mathrm{kg}$ MOF, selon Komisarczuk, 1985) et plus faibles que la moyenne des valeurs obtenues in vivo (30 à $34 \mathrm{~g} \mathrm{~N} / \mathrm{kg}$ MODR $_{\text {app. }}$ ).

Deux essais ont été menés pour comparer les résultats en Rusitec et in vivo. A Jouy, les résultats in vivo sont obtenus au niveau de la caillette. La fermentescibilité 
en Rusitec de la matière organique (calculée à partir de la production d'AGV) est proche de la digestibilité apparente de la matière organique dans le rumen. Le taux de disparition des sachets de la matière organique en Rusitec est, quant à lui, peu différent de la digestibilité de la matière organique dans le rumen corrigée pour la MO microbienne (Tableau VIII). Par contre la production d'azote microbien et le rendement de la protéosynthèse sont plus faibles d'environ $30 \%$ en Rusitec.

A Nancy, les résultats in vivo sont obtenus au niveau du duodénum. La limitation de la consommation $(900 \mathrm{~g}$ de MS par j et par mouton) est la cause de la faiblesse des flux intestinaux. Dans ces conditions, le retour de matière organique endogène dans la caillette est la cause d'une forte sous-évaluation relative de la quantité de matière organique digérée dans le rumen, apparente ou corrigée de la matière organique microbienne (Tableau VII). Le rendement de la protéosynthèse estimé in vivo est donc sur-évalué. Le rendement mesuré en Rusitec à $24 \mathrm{~h}$ de fermentation est très proche de celui obtenu à Jouy.

Les vitesses de renouvellement des phases liquide et solide sont moins élevées en Rusitec qu'in vivo. Cette différence peut expliquer que le rendement de la protéosynthèse soit plus faible en Rusitec qu'in vivo.

L'étude cinétique menée à Nancy (Tableau VII) montre que la production d'azote microbien et le rendement de la protéosynthèse peuvent passer par un maximum puis décroître. La diminution observée entre 12 et $24 \mathrm{~h}$ peut être due à un appauvrissement du milieu en facteurs de croissance.

\section{Ecosystème microbien}

L'étude des populations microbiennes en Rusitec a, à ce jour, essentiellement concerné l'évolution des protozoaires.

Tableau VIIl. Comparaison des résultats obtenus en Rusitec et in vivo pour le régime pulpe + manioc + urée + paille, en effectuant des bilans au niveau de la caillette (Jouy-en-Josas).

\begin{tabular}{lcc}
\multicolumn{1}{c}{ Mesures } & In vivo & Rusitec \\
\hline DMOR $_{\text {app. }}$ & $53 \pm 2$ & $54 \pm 1^{\mathrm{a}}$ \\
DMOR $_{\text {corr. }}$ & $71 \pm 2$ & $71 \pm 2^{\mathrm{b}}$ \\
N (microbien) en g/kg de : & & \\
MOI & $18,5 \pm 1,2$ & $12,7 \pm 0,6$ \\
MODR $_{\text {app. }}$ & $36,9 \pm 2,5$ & $23,5 \pm 1,2$ \\
MODRcorr. & $26,4 \pm 1,2$ & $17,7 \pm 0,9$ \\
\hline
\end{tabular}

DMOR : Disparition de la matière organique dans le rumen (in vivo) ou en Rusitec.

MODR = Matière organique disparue dans le rumen (in vivo) ou disparue des sachets (en Rusitec). MODR app. :apparente, c'est-à-dire sans corriger la matière organique résiduelle de la matière organique bactérienne;

MODR $_{\text {corr. }}$ : corrigée, c'est-à-dire avec correction de la matière organique résiduelle pour la matière organique bactérienne.

a : fermentescibilité de la MO calculée à partir des AGV.

b : taux de disparition des sachets. 
L'équipe de Theix a montré avec 2 substrats différents (pulpes de betteraves et son de blé) que le nombre de protozoaires présents dans le Rusitec diminue très rapidement à partir du moment de l'inoculation (Tableau IX). Cette diminution est plus forte dans le cas des gros protozoaires que dans celui des petits, ceux-ci pouvant probablement se maintenir plus facilement dans les sachets. Cette diminution est également plus rapide dans la phase liquide que dans la phase liquide associée aux solides. Cette disparition des protozoaires du fermenteur a également été observée par l'équipe de Toulouse.

Le groupe de Theix a également montré que les champignons anaérobies du rumen se développent en Rusitec. Les microbes qui adhèrent fortement aux particules alimentaires (compartiment 3 ) ont probablement une importance relative, dans l'ensemble de la biomasse microbienne, plus faible en Rusitec que dans le rumen. Cette différence s'explique par le rapport "phase solide/phase liquide" qui est environ 7 fois plus faible en Rusitec que dans le rumen.

Ces observations tendent à montrer que l'écosystème microbien du Rusitec n'est pas parfaitement identique à celui du rumen. On peut toutefois penser que les populations dominantes dans le rumen se maintiennent in vitro, puisque la simulation dans le domaine de la dégradation en $48 \mathrm{~h}$ de la matière sèche des substrats est plutôt bonne.

\section{MANIPULATION DE L'ACTIVITÉ MICRO- BIENNE}

En Rusitec, les fermentations ne sont pas influencées par la physiologie de l'animal ni par les échanges avec le compartiment sanguin. De plus, il est possible de faire fermenter seuls des aliments qui, in vivo, devraient obligatoirement être associés à d'autres, sous peine de nuire à la santé

Tableau IX. Evolution en fonction du temps du nombre total de protozoaires (nombre total par $\mathrm{ml} \mathrm{de}$ milieu) et des proportions de petits (p) et de gros $(G)$ protozoaires dans la phase liquide et dans la phase intermédiaire du Rusitec pour 2 aliments. (Theix).

\begin{tabular}{|c|c|c|c|c|c|c|c|c|c|c|c|c|}
\hline \multirow{3}{*}{\multicolumn{2}{|c|}{$\begin{array}{c}\text { Jours } \\
\text { après } \\
\text { inoculation } \\
\text { Nombre } \\
\text { total }\end{array}$}} & \multicolumn{5}{|c|}{ Pulpes de betteraves } & \multicolumn{6}{|c|}{ Son de blé } \\
\hline & & \multicolumn{2}{|l|}{$\begin{array}{l}\text { Phase } \\
\text { liquide }\end{array}$} & \multicolumn{3}{|c|}{$\begin{array}{c}\text { Phase } \\
\text { intermédiaire }\end{array}$} & \multicolumn{3}{|c|}{$\begin{array}{l}\text { Phase } \\
\text { liquide }\end{array}$} & \multicolumn{3}{|c|}{$\begin{array}{c}\text { Phase } \\
\text { intermédiaire }\end{array}$} \\
\hline & & $\begin{array}{c}p \\
(\%)\end{array}$ & $\begin{array}{c}G \\
(\%)\end{array}$ & $\begin{array}{c}\text { Nombre } \\
\text { total }\end{array}$ & $\underset{(\%)}{p}$ & $\begin{array}{c}G \\
(\%)\end{array}$ & $\begin{array}{c}\text { Nombre } \\
\text { total }\end{array}$ & $\theta \underset{(\%)}{p}$ & $\begin{array}{c}G \\
(\%)\end{array}$ & $\begin{array}{c}\text { Nombre } \\
\text { total }\end{array}$ & $\underset{(\%)}{p}$ & $\begin{array}{c}G \\
(\%)\end{array}$ \\
\hline 3 & 102 & 99 & 1 & $10^{4}$ & 80 & 20 & $10^{3}$ & 99 & 1 & $10^{4}$ & 90 & 10 \\
\hline 7 & $<10$ & 100 & 0 & $10^{3}$ & 85 & 15 & $<10$ & 100 & 0 & $10^{4}$ & 95 & 5 \\
\hline 14 & $<10$ & 100 & 0 & $10^{2}$ & 90 & 10 & $<10$ & 100 & 0 & $10^{3}$ & 97 & 3 \\
\hline 21 & $<10$ & 100 & 0 & 10 & 95 & 5 & $<10$ & 100 & 0 & 10 & 100 & 0 \\
\hline
\end{tabular}

L'inoculation amène $2 \times 10^{5}$ protozoaires par $\mathrm{ml}$, dont $80 \%$ de petits (Entodinium) et $20 \%$ de gros (Ophryoscolecidae) protozoaires. 
des animaux. Ainsi, le Rusitec permet d'étudier la fermentation propre d'un aliment et de faire le bilan des produits issus de la dégradation de ce substrat.

Certains aliments sont ainsi étudiés en Rusitec alors qu'ils ne se suffisent pas à eux-mêmes pour assurer l'activité microbienne habituellement rencontrée in vivo; leur supplémentation en différentes substances (azote, glucides, minéraux...) paraît indispensable pour atteindre in vitro l'intensité de fermentation obtenue in vivo. Ces expériences de supplémentation renseignent sur les éléments déficitaires dans un substrat donné vis à vis de l'activité microbienne. En outre, elles peuvent permettre de répondre à des questions telles que : quel est l'effet de la concentration du milieu en azote ammoniacal ou de la quantité de glucides solubles apportée sur la dégradation ef la synthèse microbienne? On peut également considérer les supplémentations comme des moyens de rechercher les effets des interactions entre aliments ou entre les aliments et suppléments, sachant bien que dans ces conditions, tous les aliments ne peuvent pas être étudiés in vitro, faute de pouvoir donner lieu à des fermentations physiologiquement normales sans supplémenta tion.

\section{Azote soluble}

En Rusitec, une supplémentation en matières azotées dégradables par addition d'urée à la salive artificielle permet de modifier les conditions de la fermentation, en compensant un déficit en azote facilement dégradable de l'aliment testé.

A Toulouse, l'effet positif sur le taux de disparition de la matière sèche, d'une supplémentation en azote soluble d'un foin de médiocre qualité a été observé pour des durées de fermentation de $24 \mathrm{~h}(33,0$ contre $23,4 \%)$ et de $48 \mathrm{~h}(46,5$ contre $34,1 \%)$. Des effets analogues ont été observés avec la supplémentation en urée de pailles traitées à l'ammoniac (Durand et al., 1986a; Ramihone et al., 1988).

Avec les pulpes de betteraves (résultats de Nancy), une augmentation de la quantité d'urée ainsi infusée s'accompagne d'une augmentation de la teneur du milieu en azote ammoniacal et d'un accroissement des taux de disparition de la matière organique $\left(T_{\mathrm{MO}}\right)$, de la fraction NDF(TD $\left.\mathrm{TDF}_{\mathrm{ND}}\right)$ et de l'azote total $\left(T D_{N T}\right)$. Pour des teneurs en azote ammoniacal comprises entre 0 et $10 \mathrm{mg} / 100 \mathrm{ml}$, les équations suivantes ont été obtenues :

$\mathrm{TD}_{\mathrm{MO}}=(11,0 \pm 1,5) \log \left(\mathrm{N}-\mathrm{NH}_{3}\right)+63,9$ $\pm 11,7(r=0,82 ; n=18)$

$\mathrm{TD}_{\mathrm{NDF}}=(12,7 \pm 1,9) \log \left(\mathrm{N}-\mathrm{NH}_{3}\right)+49,8$ $\pm 14,5(r=0,80 ; n=18)$

$\mathrm{TD}_{\mathrm{NT}}=(10,9 \pm 1,6) \log \left(\mathrm{N}-\mathrm{NH}_{3}\right)+54,7$ $\pm 12,3(r=0,80 ; n=18)$

Dans le cas d'un foin condensé de mauvaise qualité (résultats de Nancy), un résultat assez proche est obtenu pour les taux de disparition de la matière organique et de la fraction NDF, avec des teneurs en azote ammoniacal comprises entre 0 et 8 $\mathrm{mg} / 100 \mathrm{ml}$ :

$\mathrm{TD}_{\mathrm{MO}}=(6,0 \pm 0,8) \log \left(\mathrm{N}-\mathrm{NH}_{3}\right)+43,8$ $\pm 2,5(r=0,94 ; n=6)$

$\mathrm{TD}_{\mathrm{NDF}}=(6,5 \pm 0,8) \log \left(\mathrm{N}-\mathrm{NH}_{3}\right)+38,2$ $\pm 2,6(r=0,95 ; n=6)$

En revanche, pour cet aliment, le taux de disparition de l'azote total ne paraît pas lié à la teneur en azote ammoniacal du milieu.

Il a été montré à Jouy qu'une concentration moyenne d'azote ammoniacal dans les effluents de $6 \mathrm{mg} / 100 \mathrm{ml}$ pour de la paille non traitée n'assurait pas une optimisation de la dégradabilité de la matière organique. En élevant cette concentration à $12 \mathrm{mg} / 100 \mathrm{ml}$ par apport supplémentaire 
d'urée, la dégradabilité de la matière organique de cette paille non traitée s'est accrue de 11 points; l'augmentation a été de 5 points pour de la paille traitée à la soude lorsque la teneur en ammoniac des effluents est passée de 8 à $14 \mathrm{mg} / 100 \mathrm{ml}$.

L'ensemble de ces résultats obtenus en Rusitec met en valeur l'importance d'un apport permanent et relativement important d'azote soluble pour optimiser la dégradation des aliments riches en composés pariétaux.

\section{Phosphore et soufre}

Le Rusitec a été utilisé au cours de plusieurs séries d'expériences, afin de préciser les effets sur la digestion microbienne de supplémentation en phosphore (Komisarczuk, 1985; Durand et al., 1986a, b, c; Komisarczuk et al., 1986; Komisarczuk et al., 1987b; Durand et al., 1987) et en soufre (Durand et al., 1986b, c; Durand et al., 1987; Stevani et al., 1988). Dans chacune des expériences, l'élément étudié est ajouté à la solution tampon perfusée et les résultats des réacteurs supplémentés sont comparés à ceux des réacteurs subcarencés (2 réacteurs par traitement, environ 20 j d'expérience avec, selon les expériences, plusieurs répétitions).

Le Rusitec permet de mettre en évidence le rôle positif du soufre et du phosphore sur la dégradation des constituants pariétaux, notamment la cellulose, et également sur la production de protéines microbiennes. L'analyse des gaz montre, en outre, un effet légèrement dépressif de la supplémentation minérale sur la production de méthane par rapport à celle de gaz carbonique. La supplémentation de substrats riches en glucides fermentescibles ou en constituants pariétaux montre que la sub-carence en soufre réduit plutôt la pro- téosynthèse dans le premier cas et plutôt la dégradation de la matière organique et de la cellulose dans le deuxième.

La possibilité qu'offre le Rusitec d'étudier la production d'azote microbien attaché aux particules séparément de celle de la phase liquide a permis de souligner que la sub-carence minérale réduit davantage l'activité des bactéries de la phase liquide que celle des bactéries attachées. Ces dernières doivent utiliser préférentiellement les minéraux des substrats. En outre, la croissance des bactéries et l'activité des endoglucanases de la phase intermédiaire (phase 2 = inoculum constant du fermenteur) a été fortement stimulée par l'addition de soufre (Stevani et al., 1988).

Des études en cinétique de la concentration en ATP dans le réacteur renseignent sur l'effet des minéraux sur l'activité microbienne. La sensibilité de cette molécule à la sub-carence en phosphore démontrée par Komisarczuk et al. (1987b) s'observe également avec la sub-carence en soufre (Stevani et al., données non publiées) (Fig. 8).

La comparaison des effets de la subcarence en phosphore en fermenteur à flux continu et en Rusitec (Komisarczuk, 1985) montre que ces 2 systèmes conduisent à des conclusions identiques pour la plupart des paramètres. Les différences dans le mode d'apport du substrat induisent cependant quelques modifications dans les effets relatifs de la carence, notamment en ce qui concerne la MOF. Ces résultats en fermenteur à flux continu et en Rusitec confirment ceux de quelques expériences effectuées in vivo sur les subcarences en phosphore (résultats rapportés par Durand et Komisarczuk, 1988).

La réduction de la protéosynthèse observée en Rusitec lors d'une sub-carence en soufre confirme de nombreuses observations effectuées en culture "batch" ou in 


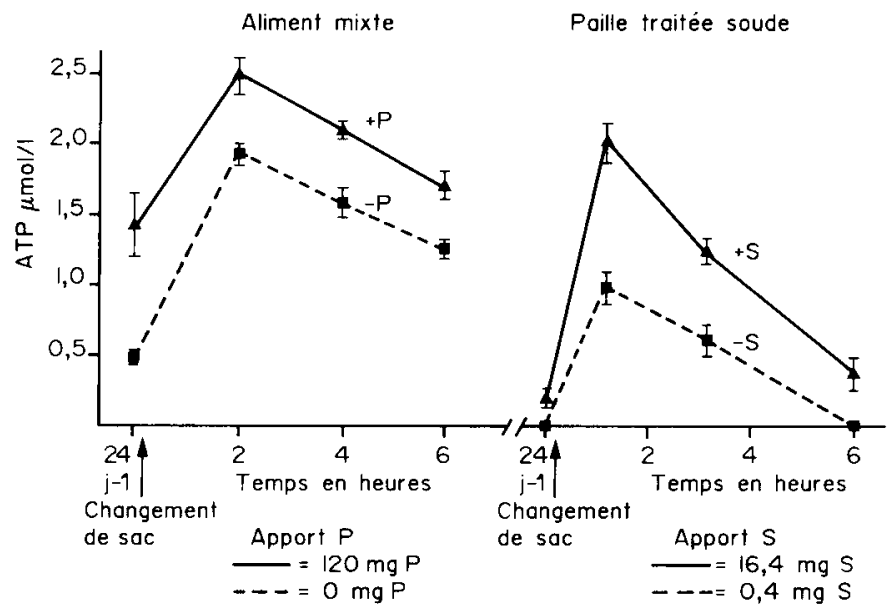

Fig. 8. Influence de l'apport de phosphore et de soufre sur l'évolution des concentrations en ATP de la phase liquide du réacteur au cours de la journée (moyenne \pm écart type de la moyenne) (Jouy-enJosas).

vivo (Durand \& Komisarczuk, 1988). Les résultats sur la sensibilité de la cellulolyse à l'apport de soufre sont en accord avec ceux de Slyter et Chalupa (1986), obtenus en culture continue, sur le nombre de bactéries cellulolytiques qui décroît fortement lors d'une sub-carence en soufre. In vivo, cette sub-carence peut également affecter la cellulolyse avec des régimes riches en ensilage de maïs ou en graminées d'origine tropicale, selon les données rapportées par Durand et Komisarczuk (1988).

En conclusion, les résultats obtenus en Rusitec sur l'apport minéral correspondent aux données in vivo, et à l'aide de ce fermenteur, le mode d'action des différents éléments peut être approfondi. Le Rusitec devrait également permettre, à l'avenir, de préciser l'apport optimal de chaque élément en fonction de la nature du substrat. Cela demandera des expérimentations relativement longues (4 à 5 j d'adaptation sont nécessaires entre chaque dose) et au-delà de 3 semaines, il existe un risque certain de déviation des fermentations. De tels essais imposeront le maintien permanent d'un fermenteur à un traitement témoin ou le retour en fin d'expérience aux conditions de la première période. II est probable que ce type d'étude est plus facile à réaliser avec les fermenteurs à flux continu, pour lesquels les périodes d'adaptation sont plus courtes (Komisarczuk et al., 1987c).

\section{Associations d'aliments}

L'étude des effets des supplémentations peut être prolongée par celle des effets provoqués par l'association d'aliments. Ainsi à Nancy un essai a été mené dans lequel le taux de disparition de l'azote total a été mesuré en Rusitec, en utilisant comme substrat soit du maïs seul, soit de la luzerne déshydratée seule, soit enfin une association maïs-luzerne (1/1). Dans 
ce dernier cas, les réacteurs étaient approvisionnés chaque jour avec un sachet contenant du mais ( $1 / 4$ du poids total de substrat), un sachet contenant de la luzerne ( $1 / 4$ du poids total de substrat) et un sachet contenant un mélange (1/1) des deux aliments ( $1 / 2$ du poids total de substrat). Les résultats sont présentés dans le Tableau $X$.

Dans cet essai, le taux de disparition de l'azote total paraît additif, dans la mesure ou la valeur du taux de disparition calculée à partir des taux de disparition des aliments fermentés seuls est très proche de la valeur mesurée sur le mélange $(75,7$ contre 73,9). Cependant, l'association des 2 aliments se traduit de fait par une augmentation du taux de disparition de l'azote total du maïs, en liaison avec une augmentation de la teneur du milieu en azote ammoniacal. Cette augmentation est compensée par une diminution du taux de disparition de l'azote total de la luzerne qui peut être attribuée à la baisse de la teneur en azote ammoniacal du milieu, par rapport à celle observée lorsque la luzerne est mise à fermenter isolément.

\section{Vitamines}

Bien qu'il soit généralement admis que les synthèses de vitamines du groupe B par la micro-population du rumen satisfont les besoins des micro-organismes et ceux des ruminants hôtes, diverses études récentes semblent montrer que certaines supplémentations vitaminiques, notamment en niacine, peuvent améliorer les performances zootechniques de l'animal. Par contre, les résultats sont contradictoires en ce qui concerne l'effet de telles supplémentations sur l'activité fermentaire du rumen in vitro comme in vivo.

L'influence de l'addition d'associations vitaminiques hydrosolubles sur la dégradation de substrats fibreux (paille, paille traitée à la soude, foin, pulpes de betteraves déshydratées) a été étudiée en Rusitec (Bouillet-Oudot et al., 1988a). Une augmentation de la dégradation des substrats les plus riches en parois végétales a pu être constatée après $24 \mathrm{~h}$ et $48 \mathrm{~h}$ de fermentation en présence de vitamines $\mathrm{B}$ ( $\mathrm{Ta}$ bleau XI). L'effet vitaminique observé a pu

Tableau X. Taux de disparition en $48 \mathrm{~h}$ de l'azote total de 2 aliments et teneurs en azote ammoniacal du milieu de fermentation avant l'approvisionnement des réacteurs en Rusitec. Aliments fermentés seuls, en association et en mélange (Nancy).

\begin{tabular}{|c|c|c|c|c|c|}
\hline \multirow{2}{*}{ Aliments } & \multicolumn{2}{|c|}{$\begin{array}{l}\text { Aliments } \\
\text { seuls }\end{array}$} & \multicolumn{2}{|c|}{$\begin{array}{l}\text { Aliments } \\
\text { associés }\end{array}$} & \multirow[t]{2}{*}{$D$} \\
\hline & $T D_{N T}$ & $\mathrm{~N}-\mathrm{NH}_{3}$ & $T D_{N T}$ & $\mathrm{~N}-\mathrm{NH}_{3}$ & \\
\hline $\begin{array}{l}\text { Maïs déshydraté } \\
\text { Luzerne déshydratée }\end{array}$ & $\begin{array}{l}58,0 \\
85,7\end{array}$ & $\begin{array}{l}0,03 \\
8,20\end{array}$ & $\begin{array}{l}71,6 \\
79,5\end{array}$ & $\begin{array}{l}1,86 \\
1,86\end{array}$ & $\begin{array}{l}+13,6 \\
-\quad 6,2\end{array}$ \\
\hline $\begin{array}{l}\text { Mélange } \quad \text { TD mesuré } \\
\text { maïs + luzerne TD calculé }\end{array}$ & $\overline{75,7}$ & $\begin{array}{l}- \\
-\end{array}$ & $\begin{array}{l}73,9 \\
76,1\end{array}$ & $\begin{array}{l}1,86 \\
-\end{array}$ & $-0,4$ \\
\hline
\end{tabular}

$D=$ Effet de l'association = TD aliment associé - TD aliment seul

$\mathrm{N}-\mathrm{NH}_{3}$ en $\mathrm{mg} / 100 \mathrm{ml}$. 
être attribué essentiellement à l'acide folique et à la choline, vitamines intervenant comme coenzymes de méthylation ou, en ce qui concerne la choline, comme constituant des membranes des protozoaires (Bouiller-Oudot et al., 1988b).

L'utilisation du Rusitec permet également de mettre en évidence des différences entre substrats des effets des supplémentations vitaminiques sur la répartition des produits de la fermentation entre AGV et gaz : avec de la paille traitée à la soude, la production d'AGV est augmentée par la supplémentation vitaminique $(45,0$ contre $36,4 \mathrm{mmol} / \mathrm{j})$ alors qu'avec un foin de graminées, c'est la production de gaz qui est accrue $(28,1 \mathrm{mmol}$ de $\mathrm{CO}_{2}$ contre 18,1 et $16,6 \mathrm{mmol}$ de $\mathrm{CH}_{4}$ contre 11,6).

Broad et Dawson (1976) ont montré que les protozoaires ont des besoins spécifiques en choline, incorporée sous forme de phosphatidylcholine dans leur membrane. Par contre, une part importante de la choline d'origine alimentaire est rapidement dégradée en triméthylamine puis en méthane par les bactéries du rumen (Neill et al., 1978; Neill et al., 1979). II est donc permis de penser qu'avec certains substrats les faibles disponibilités en choline alimentaire limitent la croissance des protozoaires. Goodson et Tuznik (1977) ont d'ailleurs observé une augmentation du nombre de protozoaires chez des moutons lorsque leur régime, à base d'ensilage de maïs, était enrichi en choline. Cependant, en Rusitec, le nombre de protozoaires diminue fortement et systématiquement pendant la phase d'adaptation, indépendamment de l'effet vitaminique. L'intensité de cet effet en Rusitec reflète donc probablement assez mal celle de l'effet observé in vivo.

\section{Antibiotiques}

L'emploi d'additifs alimentaires en tant que "facteurs de croissance» chez le Ruminant s'est largement développé au cours de la dernière décennie. Ces composés, qui ont un impact économique important pour les firmes qui les commercialisent,

Tableau XI. Effets de l'addition d'un mélange de vitamines hydrosolubles sur la dégradation de 2 substrats fibreux en Rusitec (Toulouse).

\begin{tabular}{|c|c|c|c|c|}
\hline \multirow{2}{*}{$\begin{array}{l}\text { Aliments } \\
\text { Traitements }\end{array}$} & \multicolumn{2}{|c|}{ Paille de blé } & \multicolumn{2}{|c|}{ Foin de graminées } \\
\hline & $T$ & $V$ & $T$ & $V$ \\
\hline$T_{\text {MO }}$ en $24 h$ & $15,7 \pm 0,66$ & $20,7 \pm 0,74 a$ & $32,4 \pm 0,42$ & $34,8 \pm 0,20 a$ \\
\hline$T D_{M O}$ en $48 \mathrm{~h}$ & $33,8 \pm 1,02$ & $39,6 \pm 1,11 \mathrm{a}$ & $46,2 \pm 0,92$ & $48,3 \pm 0,34$ \\
\hline$T D_{N D F}$ en $24 \mathrm{~h}$ & $14,2 \pm 0,99$ & $19,1 \pm 0,82 a$ & $18,9 \pm 0,73$ & $22,6 \pm 0,57 \mathrm{a}$ \\
\hline $\mathrm{TD}_{\mathrm{NDF}}$ en $48 \mathrm{~h}$ & $32,3 \pm 1,13$ & $37,4 \pm 0,89 a$ & $37,0 \pm 1,42$ & $40,4 \pm 0,48$ \\
\hline
\end{tabular}

Les valeurs indexées (a) diffèrent significativement $(P<0,01)$ des valeurs témoins correspondantes. Moyenne \pm écart type de la moyenne des taux de disparition de la matière organique ( $T_{\mathrm{MO}}$ ) et de la fraction NDF (TD $D_{N D F}$ ) en 24 et en $48 \mathrm{~h}$ de fermentation avec supplémentation (V) ou sans (T). 
ont fait l'objet de nombreux travaux de recherche engagés à la fois pour comprendre les mécanismes d'action et pour découvrir de nouvelles molécules dont l'activité serait plus forte ou dont la toxicité serait plus faible que celles actuellement connues (monensine, lasalocide, avoparcine). Dans ce cadre, le groupe de Theix a testé l'activité d'environ $\mathbf{4 0}$ molécules différentes au moyen de différentes techniques in vitro.

Les systèmes in vitro permettent de s'affranchir de «l'effet animal» et de gommer le caractère de toxicité des additifs. En outre, ils présentent l'avantage de pouvoir réaliser les essais avec des quantités faibles de produits (quelques centaines de $\mathrm{mg}$ ) alors que plusieurs $\mathrm{g}$ sont nécessaires in vivo. Le système de type "fermé" développé par Jouany et Thivend (1986) convient pour faire des séries importantes de criblage des molécules disponibles en faible quantité (moins de $10 \mathrm{mg}$ ). Toutefois, cette technique n'est utilisable que pendant de courtes périodes d'incubation (6 h au maximum). Par rapport au système "fermé", le Rusitec présente l'avantage majeur de donner des résultats en présence d'une micro-population adaptée à l'additif. L'adaptation peut être réalisée au sein même du fermenteur, ce qui permet de suivre l'évolution dans le temps des réactions d'une population microbienne du rumen n'ayant jamais été au contact de l'additif testé. Les mesures en Rusitec peuvent également être effectuées sur un inoculum microbien provenant d'animaux préalablement adaptés au composé destiné à être étudié. Les essais qui ont été effectués sur Rusitec par le groupe de Theix dans les 2 situations décrites précédemment ont montré que la nature de l'inoculum microbien n'est pas un facteur déterminant pour les effets que peut avoir un antibiotique sur les fermentations. Ce résultat est particulièrement intéressant puis- que le caractère facultatif de l'adaptation préalable des animaux fournissant l'inoculum permet d'épargner des quantités notables de produit.

Deux critiques importantes peuvent être formulées à l'égard du Rusitec en tant que modèle in vitro simulant les réactions des microbes du rumen en présence d'additifs. Tout d'abord, il est difficile d'apprécier les doses optimales d'activité des molécules avec ce dispositif. En effet, la dilution importante, par rapport au contenu de rumen (environ 7 fois), de la matière sèche dans la phase liquide du Rusitec complique sérieusement la transposition à l'animal des résultats obtenus in vitro. Ainsi un additif incorporé à raison de 30 ppm dans l'aliment (cas des antibiotiques ionophores) se retrouve dans le rumen à la concentration de $3,5 \mathrm{mg} / \mathrm{l}$ de contenu alors qu'il ne représente que $0,45 \mathrm{mg} / \mathrm{l}$ dans le Rusitec. Les tests doivent-ils être effectués en fonction de la dose de l'additif dans le fermenteur ou de sa concentration dans l'aliment? A priori, on est tenté de penser qu'il est plus important de respecter la concentration dans le milieu fermentaire, cette dernière étant plus apte à modifier l'équilibre microbien du milieu. C'est ainsi que Wallace et al. (1980) et Wallace et al. (1981) ont testé en Rusitec, les effets du monensine avec des doses respectives de $33 \mathrm{mg} / \mathrm{l}$ ou de $2,411,9$ et $59 \mathrm{mg} / \mathrm{l}$, alors que Fuller et Johnson (1981) ont utilisé le monensine et le lasalocide aux concentrations de 1,2 et $4 \mathrm{mg} / \mathrm{l}$. Une étude, au cours de laquelle la dose de l'additif varie entre ces 2 situations (de 0,5 à $40 \mathrm{mg} / \mathrm{l}$ ) est en cours de réalisation par le groupe de Theix.

La deuxième réserve concerne l'élimination partielle des protozoaires et l'absence de la micro-population de la paroi du rumen dans le Rusitec, ce qui limite la validité des réponses obtenues dans le cas où les additifs étudiés ont une action spécifique à l'égard de ces constituants de l'écosystème microbien. 
Afin d'étudier le comportement d'un tel système in vitro, le groupe de Theix a testé l'action de 3 antibiotiques ionophores (lasalocide, cationomycine et abiérixine) à la fois sur des moutons porteurs de canules du rumen et en Rusitec ensemencé avec des contenus de rumen provenant de ces mêmes animaux. Les résultats montrent que les modifications des paramètres fermentaires observées in vitro et in vivo, lorsqu'elles sont statistiquement significatives, évoluent dans le même sens ( $\mathrm{Ta}$ bleau XII). Toutefois, les changements attribués à la présence des antibiotiques sont quantitativement plus importants en Rusitec qu'in vivo.

La population à l'équilibre dans le Rusitec paraît être plus sensible aux additifs que celle du rumen. Ainsi, l'augmentation de la production de propionate au détriment de l'acétate et surtout du butyrate, liée à la présence d'antibiotique ionophore, est-elle nettement supérieure en Rusitec (Tableau XII). Cette évolution qui est corroborée par la diminution également plus nette de la proportion de méthane dans le mélange gazeux produit en Rusitec, augmente les écarts déjà signalés dans la composition des produits terminaux de la fermentation (AGV et gaz) entre animaux et Rusitec.

L'ensemble de ces résultats indique que les réactions des micro-organismes anaérobies du rumen évoluent lorsque ceux-ci sont placés dans le fermenteur Rusitec. Ce modèle expérimental est plus sensible que le rumen pour mettre en évidence des différences qualitatives dues à la présence d'additif. Cette propriété en fait donc un outil particulièrement discriminant pour comparer l'activité de diverses molécules. Toutefois, les données quantitatives devront être interprétées avec prudence et

Tableau XII. Effet comparé des antibiotiques ionophores sur les paramètres fermentaires mesurés en Rusitec et chez le mouton (\% des résultats obtenus sans additif) (Theix).

\begin{tabular}{|c|c|c|c|c|c|c|}
\hline \multirow{2}{*}{$\begin{array}{l}\text { Antibiotiques } \\
\text { Méthodes }\end{array}$} & \multicolumn{2}{|c|}{ Lasalocide } & \multicolumn{2}{|c|}{ Cationomycine } & \multicolumn{2}{|c|}{ Abierixine } \\
\hline & In vivo & Rusitec & In vivo & Rusitec & In vivo & Rusitec \\
\hline $\mathrm{pH}$ & $-0,1$ & $-0,3$ & $-0,1$ & $-0,1$ & 0 & 0 \\
\hline $\mathrm{AGV}(\mathrm{mmol} / \mathrm{l})$ & $-1,0$ & $+8,7$ & $-0,7$ & $+5,3$ & $+7,9$ & $+6,2$ \\
\hline dont $\mathrm{C}_{2}(\%)$ & $-4,5^{\star}$ & $-6,9^{*}$ & $+0,1$ & $-11,1^{\circ}$ & 0 & $-5,6$ \\
\hline $\mathrm{C}_{3}(\%)$ & $+21,8^{*}$ & $+37,4^{\star *}$ & $+21.2^{*}$ & $+47,7^{* *}$ & $-2,7$ & $-13,3$ \\
\hline $\mathrm{C}_{4}(\%)$ & $-11,0^{\star}$ & $-37,6^{\star \star}$ & $-18,3$ * & $-36,3^{\star *}$ & $-8,3$ & $-8,7$ \\
\hline$I C_{4}+I C_{5}(\%)$ & $-3,1$ & $+5,7$ & $-7,1$ & $-42,1^{* *}$ & $-11,1$ & 0 \\
\hline $\mathrm{C}_{5}(\%)$ & 0 & $+14,6^{*}$ & $-6,9$ & $+60,1^{\star *}$ & $-13,3$ & $+33,3^{*}$ \\
\hline $\mathrm{C}_{2} / \mathrm{C}_{2}+\mathrm{C}_{3}$ & $-5,1^{\star}$ & $-11,4^{* *}$ & $-3,7^{*}$ & $-15,1^{\star \star}$ & $-0,9$ & $-2,6$ \\
\hline $\mathrm{CH}_{4} / \mathrm{CO}_{2}+\mathrm{CH}_{4}$ & $-6,3^{*}$ & $-20,9^{\star *}$ & $-3,9^{*}$ & $-33,0^{* *}$ & $-3,2$ & $-5,9$ \\
\hline
\end{tabular}

* Effet significatif à $P<0,05$.

** Effet significatif à $P<0,01$. 
ne pourront pas être extrapolées sans réserves à l'animal.

\section{CONCLUSION}

La mise en commun des résultats obtenus sur Rusitec dans 5 stations françaises et leur confrontation avec les résultats obtenus à l'étranger permettent de mettre en évidence les intérêts et les limites de l'utilisation de ce type de fermenteur.

Les modalités de fonctionnement diffèrent généralement assez peu entre laboratoires. Cependant, une partie des matériels et des méthodes peut être modifée en fonction des objectifs de recherche. C'est spécialement le cas de la qualité du tissu servant à fabriquer les sachets, dont la porosité est en grande partie choisie en fonction de la nécessité ou non de laver les sachets $(50$ ou $150 \mu \mathrm{m})$. L'addition de minéraux ou d'une source d'azote dans la solution saline dépend également des buts recherchés. En revanche, les différences de taux de renouvellement de la phase liquide $\left(0,65\right.$ à $\left.1,00 j^{-1}\right)$ se justifient moins facilement.

La variabilité entre jours du taux de disparition de la matière sèche (moyenne du coefficient de variation $=8,8 \%$ sur 97 mesures), des quantités d'AGV produites et les volumes de gaz dégagés, oblige à recommander la répétition des mesures : au moins 4 j et 2 réacteurs. Dans ces conditions, les résultats sont bien répétables entre stations. Le paramètre le moins variable entre jours semble bien être la composition du mélange d'AGV produits.

II est possible que des déviations des fermentations se produisent, à la suite d'une sélection des souches présentes, spécialement au cours d'expériences de longue durée lorsque les conditions ne sont pas pleinement favorables. II peut être alors prudent de limiter la durée des essais (environ $20 \mathrm{j}$ ) et surtout de vérifier in vitro (périodes témoins) ou par rapport à des résultats obtenus in vivo la stabilité du fonctionnement du fermenteur. Ces précautions sont d'autant plus indispensables que l'on s'écarte des conditions habituelles de la nutrition des microbes (aliments carencés ou très riches, supplémentations excessives...).

L'utilisation du Rusitec présente un certain nombre d'inconvénients. Le plus évident est l'utilisation de sachets, pourtant indissociable de la méthode : la taille des mailles et ses répercussions sur la circulation des fluides et les pertes particulaires peuvent être mises en cause, tout comme dans la technique des sachets.

Les études cinétiques de la disparition des substrats sont difficiles à réaliser et exigeantes en travail. Les problèmes de déviation des fermentations qu'elles sont susceptibles d'occasionner semblent avoir été résolus avec les réacteurs de plus grande capacité $(x 2,5)$, qui présentent probablement une plus grande inertie aux conditions défavorables.

Pour les paramètres sur lesquels il est possible de la vérifier, il existe généralement une bonne concordance entre les résultats en Rusitec et ceux obtenus chez l'animal. Pour la synthèse protéique, qui peut être évaluée grâce à l'utilisation des différents marqueurs connus, à condition de pratiquer les mesures dans tous les compartiments du fermenteur, les résultats obtenus aboutissent à des rendements calculés inférieurs à ceux fournis par le système à flux continu et par les mesures in vivo.

Le rythme d'alimentation (1 repas par jour) est probablement de nature à introduire des différences avec les résultats in 
vivo. II a probablement aussi comme conséquence de sous-alimenter les microorganismes au cours des périodes éloignées du moment de l'approvisionnement. A ce titre, le Rusitec est certainement mieux adapté à des études utilisant des substrats lentement dégradables (fourrages) qu'à celles utilisant des concentrés.

II faut cependant souligner que l'utilisation d'un système de fermentation continue comme le Rusitec est coûteuse et laborieuse. Aussi apparaît-il illogique de l'employer pour des mesures de dégradabilité en séries qui peuvent être réalisées chez l'animal par la méthode des sachets avec beaucoup moins de contraintes.

Le Rusitec permet de mesurer simultanément la plupart des paramètres de la fermentation : caractéristiques de dégradation du substrat (taux de disparition de la matière sèche et de ses constituants), faciès fermentaire (AGV, gaz, ammoniac), synthèse microbienne. Ces mesures peuvent être pratiquées en tenant compte des aspects cinétiques de la fermentation, le temps de séjour de l'aliment étant parfaitement déterminé, et aboutir aussi à l'établissement de bilans de fermentation. C'est l'avantage majeur du Rusitec sur les techniques in vivo, avec lesquelles les aspects quantitatifs sont difficiles à maîtriser, et sur les systèmes à flux continu qui fournissent essentiellement des bilans.

Le Rusitec peut spécialement être valorisé dans l'étude de facteurs susceptibles de modifier les activités fermentaires. Les essais effectués à ce jour ont ainsi permis de caractériser l'influence de l'infusion d'urée, et par conséquent de la teneur du milieu en ammoniac, sur la dégradation de substrats paurres en azote, les effets des sub-carences en phosphore et en soufre sur la dégradation des substrats et la protéosynthèse, les effets de l'addition de vitamines ou d'antibiotiques ionophores sur l'ensemble des paramètres de la fermentation.

En conclusion, le Rusitec doit être considéré comme une méthode complémentaire de celles utilisées in vivo en vue d'approfondir la connaissance du métabolisme microbien dans le rumen.

\section{RÉFÉRENCES}

Bauchart D., Legay-Carmier F., Doreau M. \& Jouany J.P. (1986) Effets de l'addition de matières grasses non protégées à la ration de la vache laitière sur la concentration et la composition chimique des bactéries et des protozoaires du rumen. Reprod. Nutr. Dev. 26, 309-310

Blanchart G. \& Vignon B. (1984) Adaptation d'un fermenteur de type Rusitec. Cah. Techn. INRA 9, 1-10

Bouiller-Oudot M., Belfadla A. \& Candau M. (1988a) Influence de l'addition de vitamines du groupe B sur la dégradation des constituants pariétaux (paille, foin, pulpe) par les microorganismes du rumen en fermenteur semi-continu. Reprod. Nutr. Dev. 28, 171-172

Bouiller-Oudot M., Belfadla A., Tahar J. \& Candau M. (1988b) Influence de l'addition de vitamines hydrosolubles sur la dégradation des substrats riches en constituants pariétaux par les microorganismes du rumen en fermenteur semicontinu (soumis à publication)

Brice R.E. \& Morrison L.M. (1983) Digestion of grass stem in nylon bags of different pore size in an artificial rumen (Rusitec). Proc. Nutr. Soc. 42, $30 \mathrm{~A}$

Broad T.E. \& Dawson R.M.C. (1976) Role of choline in the nutrition of the rumen protozoon Entodinium caudatum. J. Gen. Microbiol. 92, 391-397

Czerkawski J.W. (1984) Microbial fermentation in the rumen. Proc. Nutr. Soc. 43, 101-118

Czerkawski J.W. \& Breckenridge G. (1977) Design and development of a long-term rumen simulation technique (Rusitec). Br. J. Nutr. 38, 371384 
Czerkawski J.W. \& Breckenridge G. (1979a) Experiments with the long-term rumen simulation technique (Rusitec): response to supplementation of basal rations. $\mathrm{Br}$. J. Nutr. 42, 217-228

Czerkawski J.W. \& Breckenridge G. (1979b) Experiments with the long-term rumen simulation technique (Rusitec): use of soluble food and an inert matrix. Br. J. Nutr. 42, 229-245

Czerkawski J.W. \& Breckrenridge G. (1982) Distribution and changes in urease (EC. 3.5.1.5.) activity in rumen simulation technique (Rusitec). Br. J. Nutr. 47, 331-348

Czerkawski J.W. \& Breckenridge G. (1985) Metabolism of protein supplements studied by the rumen simulation technique (Rusitec). Arch. Tierernähr. 35, 261-277

Durand M. (1987) Conditions for optimizing celIulolytic activity in the rumen. In: Methods of Evaluation of Straw in Ruminant Feeding. CEE COST 84 bis Workshop, Theix, France, 2-4 June, 1987. CEC Report (in press)

Durand M., Beaumatin Ph., Dumay C., Meschy F. \& Komisarczuk S. (1986a) Influence de l'addition de phosphore sur la digestion d'une paille traitée à l'ammoniac par les microorganismes du rumen en fermenteur semi-continu (Rusitec). Reprod. Nutr. Dev. 26, 297-298

Durand M., Hannequart G., Beaumatin Ph. \& Dumay C. (1986b) Use of the rumen simulation technique (Rusitec) to study the effect of type of feedstuffs and mineral supply on microbial protein synthesis. Arch. Anim. Nutr. (Berlin) 36, 327

Durand M., Hannequart G., Beaumatin Ph., Dumay C. \& Tassery F. (1986c) Influence du niveau d'apport de soufre sur la synthèse d'acide ribonucléique et de protéines par les microorganismes du rumen en fermenteur semi-continu. Reprod. Nutr. Dev. 26, 299-300

Durand M., Stevani J. \& Komisarczuk S. (1987) Effect of some major minerals on rumen microbial metabolism in a semi-continuous fermentor (Rusitec). Med. Fac. Landbouww. Rijksuniv. Gent 52, 1655-1663

Durand M., Dumay C., Beaumatin Ph. \& Morel M.-T. (1988) Use of the rumen simulation technique (Rusitec) to compare microbial digestion of various by-products. Anim. Feed Sci. Technol. 21, 197-204

Durand M. \& Komisarczuk S. (1988) Influence of major minerals on rumen microbiota. J. Nutr. $118,249-260$
Fonty G. (1984) Implantation de la microflore et des protozoaires ciliés dans le rumen d'agneaux holoxéniques et néo-holoxéniques. Facteurs écologiques déterminant l'implantation de Bacteroïdes succinogenes (S85) et des protozoaires ciliés dans le rumen d'agneaux holoxéniques isolés, d'agneaux méroxéniques et d'agneaux gnotoxéniques. Evolution des principaux paramètres digestifs. Thèse de Doc. Univ. ClermontFerrand, $235 \mathrm{pp}$.

Fuller J.R. \& Johnson D.E. (1981) Monensin and lasalocid effects on fermentation in vitro. $J$. Anim. Sci. 53, 1574-1580

Goering H.K. \& Van Soest P.J. (1970) Forage fiber analysis. Agriculture Handbook, $\mathrm{N}^{\circ} 379,1-$ 19, Agricultural Research Service, US Department of Agriculture

Goodson J. \& Tuznik W.J. (1977) Effect of supplemental choline chloride on the rumen microbial populations of sheep. J. Anim. Sci. 45 (Suppl. 1), 237

Guy C., Jouany J.P. \& Gros J.B. (1988) Bilan des éléments $\mathrm{CHON}$, à l'entrée et à la sortie d'un fermenteur semi-continu (Rusitec) en fonction du taux de renouvellement de la phase liquide. Reprod. Nutr. Dévelop. 28, 145-146

Hoover W.H., Crooker B.A. \& Sniffen C.J. (1976) Effects of differential solid-liquid removal rates on protozoa numbers in continuous cultures of rumen contents. J. Anim. Sci. 43, 528534

Jouany J.P. \& Thivend P. (1986) In vitro effects of avoparcin on protein degradability and rumen fermentation. Anim. Feed Sci. Technol. 15, 215229

Komisarczuk S. (1985) Etude de l'influence du phosphore sur l'activité fermentaire, la protéosynthèse et les teneurs en ATP de contenus de rumen dans différents systèmes de culture continue. Thèse de Doctorat en Sciences, Univ. Paris-Sud, Centre d'Orsay, 200 pp.

Komisarczuk S., Durand M., Dumay C. \& Morel M.-T. (1986) Use of a semi-continuous culture system (Rusitec) to study the effect of phosphorus deficiency on rumen microbial digestion. In: Biology of Anaerobic Bacteria (Dubourguier H.C., ed.) Elsevier, Amsterdam, 47-53

Komisarczuk S., Durand M., Beaumatin Ph. \& Hannequart G. (1987a) Utilisation de l'azote 15 pour la mesure de la protéosynthèse microbi- 
enne dans les phases solide et liquide d'un fermenteur semi-continu (Rusitec). Reprod. Nutr. Dev. 27, 261-262

Komisarczuk S., Durand M., Beaumatin Ph. \& Hannequart G. (1987b) Effect of phosphorus deficiency on rumen microbial activity associated with the solid and liquid phases of a fermentor (Rusitec). Reprod. Nutr. Dev. 27, 907-919

Komisarczuk S., Merry R.J. \& McAllan A.B. (1987c) Effect of different levels of phosphorus on rumen microbial fermentation and synthesis determined using a continuous culture technique. Br. J. Nutr. 57, 279-290

McDougall E.I. (1948) Studies on ruminant saliva. 1. Composition and output of sheep's saliva. Biochem. J. 43, 99-109

Merry R.J. \& McAllan A.B. (1983) A comparison of the chemical composition of mixed bacteria harvested from the liquid and solid fractions of rumen digesta. Br. J. Nutr. 50, 701-709

Merry R.J., Smith R.H. \& McAllan A.B. (1987) Studies of rumen function in an in vitro continuous culture system. Arch. Anim. Nutr. (Berlin) 6, 475-488

Morrison I.M. \& Brice R.E. (1984) The digestion of untreated and ammonia-treated barley straw in an artificial rumen. Anim. Feed Sci. Technol. $10,229-238$

Neill A.R., Grime D.W. \& Dawson R.M.C. (1978) Conversion of choline methyl groups through trimethylamine into methane in the rumen. Biochem. J. 170, 529-535

Neill A.R., Grime D.W., Snoswell A.M., Northrop A.J., Lindsay D.B. \& Dawson R.M.C. (1979) The low availability of dietary choline for the nutrition of the sheep. Biochem. J. 180, 559-565

Ramihone B., Jouany J.P. \& Chenost M. (1988) Part de l'azote apporté par le traitement à l'ammoniac dans la digestion microbienne d'une paille de blé en fermenteur semi-continu (Rusitec). Reprod. Nutr. Dev. 28, 151-152

Schaetzel W.P. \& Johnson D.E. (1981) Nicotinic acid and dilution rate effects on in vitro fermentation efficiency. J. Anim. Sci. 53, 1104-1108

Slyter L.L. \& Chalupa W. (1986) Sulfur influences on rumen microorganisms in vitro and in sheep and calves. J. Anim. Sci. 63, 1949-1959

Smith R.H., McAllan A.B., Hewitt D. \& Lewis P.E. (1978) Estimation of amounts of microbial and dietary nitrogen compounds entering the duodenum of cattle. J. Agric. Sci. Camb. 90, 557568

Stanier G. \& Davies A. (1981) Effect of the antibiotic monensin and an inhibitor of methanogenesis on in vitro continuous rumen fermentations. Br. J. Nutr. 45, 567-578

Stevani J., Beaumatin Ph., Dumay C., Hannequart G. \& Durand M. (1988) Etude en fermenteur semi-continu de l'influence de l'addition de sulfate sur la dégradation des constituants pariétaux d'une paille non traitée ou traitée à la soude. Reprod. Nutr. Dev. (à paraître)

Stevens C.E. (1970) Fatty acid transport through the rumen epithelium. In: Physiology of Digestion and Metabolism in the Ruminant (Phillipson A.T., ed.), Oriel Press, Newcastle, 101112

Tisserand J.L. \& Zelter S.Z. (1965) Essai de normalisation d'une technique de mesure de la digestion des fourrages in vitro "rumen artificiel". Ann. Biol. Anim. Bioch. Biophys. 5, 101-111

Wallace R.J., Cheng K.J. \& Czerkawski J.W. (1980) Effect of monensin on fermentation characteristics of the artificial rumen. Appl. Environ. Microbiol. 40, 672-674

Wallace R.J., Czerkawski J.W. \& Breckenridge G. (1981) Effect of monensin on the fermentation of basal rations in the rumen simulation technique (Rusitec). Br. J. Nutr. 46, 131-148 